\title{
Unsteady MHD Convective Heat and Mass Transfer Flow in a Vertical Wavy Channel with Oscillatory Wall Temperature and Concentration
}

\author{
Shaik Sharmila $^{1}$, R. Mabunni ${ }^{2}$, G. Haripriya $^{3}$ and Prof. R. Siva Prasad ${ }^{1}$ \\ ${ }^{1}$ Academic Consultant, Department of Mathematics, Sri Krishnadevaraya University,Ananthapuramu-515003, \\ Andhra Pradesh, India.Email : gousehalima@gmail.com \\ ${ }^{2}$ School Asst., ZPHS, Maidukur (M), YSR (Dist.,) Andhra Pradesh, India \\ ${ }^{3}$ Asst. Prof. in Mathematics, Gates Engg. College, Gooty, Ananthapuramu (Dist.,), \\ Andhra Pradesh, India
}

\begin{abstract}
In this paper, we make an attempt to analyse the unsteady convective heat and mass transfer flow of viscous, electrically conducting fluid confined in a vertical channel on whose walls an oscillatory temperature and concentration are prescribed. Approximate solutions to coupled non-linear partial differential equations governing the flow, heat and mass transfer are solved by a perturbation technique. The velocity, temperature, concentration and rate of heat and mass transfer are discussed for different variations of $\mathrm{G}, \mathrm{M}, \mathrm{D}^{-1}, \alpha, \beta, \gamma, \mathrm{k}, \mathrm{N}$, Sc, and $\mathrm{x}$.
\end{abstract}

Keywords: Magnetohydrodynamics, Vertical wavy channel, Heat and Mass Transfer flow, Oscillatory wall temperature and concentration

\section{INTRODUCTION}

The study of flow through porous medium is of great physical interest because of its wide application in diverse fields. A number of hydrologists, geophysicists, petroleum geologists, chemical engineers have studied the flow of a porous medium. This study is also useful to understand the mechanism of transfer of heat from the deep interior of the search to a shallow depth in the geothermal region which is of vital importance in the present day grave power crisis. The sand structures in earth, filter beds for purification of drinking water, sewage are the subject of study of hydrology. The production of petroleum and gases, well drilling and logging are studied in petroleum technology.

Coupled heat and mass transfer phenomenon in porous media is gaining attention due to its interesting applications. The flow phenomenon is relatively complex rather than that of the pure thermal convection process. Underground spreading chemical wastes and other pollutants, grain storage, evaporation cooling and solidification are the few other application areas where the combined thermo-solutal natural convection in porous media are observed. Combined heat and mass transfer by free convection under boundary layer approximations has been studied by Bejan and Khair(2), Lai and Kulacki(14) and Murthy and Singh(20). Coupled heat and mass transfer by mixed convection in Darcian fluid-saturated porous media has been analysed by Lai(13). The free convection heat and mass transfer in a porous enclosure has been studied recently by Angirasa et al(1). The combined effects of thermal and mass diffusion in channel flows has been studied in recent times by a few authors, notably Nelson and $\operatorname{Wood}(25,26)$, Lee at al(17).
In recent years, energy and material saving considerations have prompted an expansion of the efforts at producing efficient heat exchanger equipment through augmentation of heat transfer. It has been established by Gagan(8) that channels with diverging-converging geometries augment the transportation of heat transfer and momentum. As the fluid flows through a tortuous path viz., the dilated - constricted geometry, there will be more intimate contact between them. The flow takes place both axially (primary) and transversely (secondary) with the secondary velocity being towards the axis in the fluid bulk rather than confining within a thin layer as in straight channels. Hence it is advantageous to go for convergingdiverging geometries for improving the design of heat transfer equipment. Vajravelu and Nayfeh(38) have investigated the influence of the wall waviness on friction and pressure drop of the generated coquette flow. Vajravelu and Sastry(39) have analysed the free convection heat transfer in a viscous, incompressible fluid confined between long vertical wavy walls in the presence of constant heat source. Later Vajravelu and Debnath(40) have extended this study to convective flow in a vertical wavy channel in four different geometrical configurations. This problem has been extended to the case of wavy walls by McMichael and Deutsch(19), Deshikachar et al(6), Rao et al(29) and Sree Ramachandra Murthy(33). Hyan Goo Kwon et al(11) have analyzed that the Flow and heat/mass transfer in a wavy duct with various corrugation angles in two dimensional flow regimes. Mahdy et al(18) have studied the mixed convection heat and mass transfer on a vertical wavy plate embedded in a saturated porous media(PST/PSE). Comini et al(4) have analyzed the Convective heat and mass transfer in wavy finned-tube exchangers. Jer-Huan Jang et 
al(12)have analyzed that the mixed convection heat and mass transfer along a vertical wavy surface. Muthuraj et.al(23) have consider mixed heat and mass transfer through a vertical wavy channel with porous medium. Kumar(16) has investigated two-dimensional heat transfer of a free convective MHD flow with radiation and temperature dependent heat sources of a viscous incompressible fluid, in a vertical wavy channel.

In many chemical engineering processes, there does occur the chemical reaction between a foreign mass and the fluid in which the plate is moving. These processes take place in numerous industrial applications viz., polymer production, manufacturing of ceramics or glassware and food processing. Das et al(7) have studied the effects of mass transfer on flow past an impulsively started infinite vertical plate with constant heat flux and chemical reaction. Muthukumaraswamy (22) has studied the effects of reaction on a long surface with suction. Gnaneswar(9) has studied radiation and mass transfer on an unsteady two-dimensional laminar convective boundary layer flow of a viscous incompressible chemically reacting fluid along a semi-infinite vertical plate with suction by taking into account the effects of viscous dissipation.

The present trend in the field of chemical reaction analysis is to give a mathematical model for the system to predict the reactor performance. A large amount of research work has been reported in this field. In particular the study of heat and mass transfer with chemical reaction is of considerable importance in chemical and hydrometallurgical industries. Chemical reaction can be codified as either heterogeneous or homogeneous processes. This depends on whether they occur at an interface or as a single phase volume reaction. Frequently the transformations proceed in a moving fluid, a situation encountered in a number of technological fields. A common area of interest in the field of aerodynamics is the analysis of thermal boundary layer problems for two dimensional steady and incompressible laminar flow passing a wedge. Simultaneous heat and mass transfer from different geometrics embedded in a porous media has many engineering and geophysical application such as geothermal reservoirs, drying of porous solids thermal insulation, enhanced oil recovery, packed-bed catalytic reactors, cooling of nuclear reactors, and under ground energy transport. A very significant area of research in radiative heat transfer, at the present time is the numerical simulation of combined radiation and convection/conduction transport processes. The effort has arisen largely due to the need to optimize industrial system such as furnaces, ovens and boilers and the interest in our environment and in no conventional energy sources, such as the use of salt-gradient solar ponds for energy collection and storage. In particular, natural convection induced by the simultaneous action of buoyancy forces resulting from thermal and mass diffusion is of considerable interest in nature and in many industrial application such as geophysics, oceanography, drying process, solidification of binary alloy and chemical engineering. Kandaswamy et al (15)have discussed the effects of chemical reaction, heat and mass transfer on boundary layer flow over a porous wedge with heat radiation in the presence of suction or injection.

\section{FORMULATION AND SOLUTION OF THE PROBLEM}

We consider the unsteady flow of a viscous incompressible electrically conducting fluid in a vertical wavy channel bounded by wavy walls in the presence of constant heat sources. The unsteadiness in the flow is due to the oscillatory temperature and concentration prescribed on the boundaries. We choose a Cartesian coordinate system 0 (x y) with walls at $y= \pm L f(\delta x / L)$. By using Boussinesq approximation we consider the density variation only on the buoyancy term also the kinematic viscosity $\mathrm{v}$, the thermal conductivity $\mathrm{k}$ are treated as constants. The equation governing the flow, heat and mass transfer are

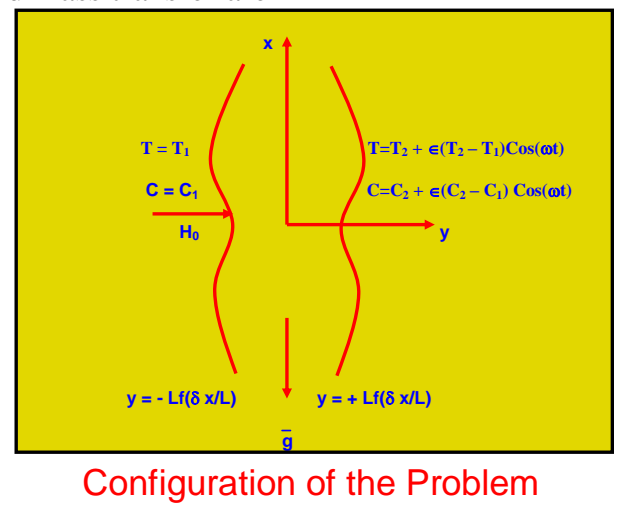

$$
\begin{aligned}
& \frac{\partial u}{\partial t}+u \frac{\partial u}{\partial x}+v \frac{\partial u}{\partial y}=-\frac{1}{\rho} \frac{\partial p}{\partial x}+ \\
& \frac{\mu}{\rho}\left(\frac{\partial^{2} u}{\partial x^{2}}+\frac{\partial^{2} u}{\partial y^{2}}\right)-\left(\frac{\mu}{k}\right) u\left(\frac{\sigma \mu_{e}^{2} H_{o}^{2}}{\rho_{o}}\right) u-\rho \bar{g} \\
& \frac{\partial v}{\partial t}+u \frac{\partial v}{\partial x}+v \frac{\partial v}{\partial y}=-\frac{1}{\rho} \frac{\partial p}{\partial y} \\
& +\frac{\mu}{\rho}\left(\frac{\partial^{2} v}{\partial x^{2}}+\frac{\partial^{2} v}{\partial y^{2}}\right)-\left(\frac{\mu}{k}\right) v \\
& \rho_{0} C\left(\frac{\partial T}{\partial t}+u \frac{\partial T}{\partial x}+v \frac{\partial T}{\partial y}\right) \\
& =k_{f}\left(\frac{\partial^{2} T}{\partial x^{2}}+\frac{\partial^{2} T}{\partial y^{2}}\right)+Q-\frac{\partial\left(q_{R}\right)}{\partial y} \\
& \left(\frac{\partial C}{\partial t}+u \frac{\partial C}{\partial x}+v \frac{\partial C}{\partial y}\right)=D_{1}\left(\frac{\partial^{2} C}{\partial x^{2}}+\frac{\partial^{2} C}{\partial y^{2}}\right)-K^{\prime} C
\end{aligned}
$$

$\rho-\rho_{0}=-\beta_{0} \rho_{0}\left(T-T_{1}\right)-\beta^{\bullet}\left(C-C_{1}\right)$

where $\mathrm{u}$ and $\mathrm{v}$ are the velocity components in $\mathrm{x}$ and $\mathrm{y}$ directions respectively, $\mathrm{T}$ is a temperature, $\mathrm{C}$ is the 


\section{E-ISSN: 2321-9637}

\section{Available online at www.ijrat.org}

Concentration, $\mathrm{p}$ is a pressure, $\rho$ is a density, $\mathrm{k}$ is the permeability of the porous medium, $\mu$ is dynamic viscosity, $\mathrm{k}_{\mathrm{f}}$ is coefficient of thermal conductivity, $\beta$ is coefficient of volume expansion, $\beta^{\bullet}$ is the coefficient of expansion with concentration, D1 is the molecular diffusivity, $K^{\prime}$ is the coefficient of chemical reaction, $\mathrm{qr}$ is the radiative heat flux and $\mathrm{Q}$ is the strength of heat source

The boundary conditions are

$\mathrm{u}=0, \mathrm{v}=0, \mathrm{~T}=\mathrm{T}_{1}, \mathrm{C}=\mathrm{C} 1 \quad$ at $\mathrm{y}=-\mathrm{Lf}(\delta \mathrm{x} / \mathrm{L})$

$\mathrm{u}=0, \quad \mathrm{v}=0, \quad \mathrm{~T}=\mathrm{T}_{1}+\in\left(\mathrm{T}_{2}-\mathrm{T}_{1}\right) \cos (\omega \mathrm{t}), \quad \mathrm{C}=\mathrm{C}_{1}+\in\left(\mathrm{C}_{2}-\right.$ $\left.\mathrm{C}_{1}\right) \cos (\omega \mathrm{t})$ on $\mathrm{y}=+\mathrm{Lf}(\delta \mathrm{x} / \mathrm{L})(6)$

The flow is driven by a constant flux given by

$q=\frac{1}{L} \int_{-L f}^{L f} u d y$

Eliminating the pressure between the equations(1)\&(2) and introducing the stream function $\psi$ defined by $u=\frac{\partial \psi}{\partial y}, v=-\frac{\partial \psi}{\partial x}$ the resulting equation is

$$
\begin{aligned}
& \frac{\partial\left(\nabla^{2} \psi\right)}{\partial t}+\frac{\partial \psi}{\partial y} \frac{\partial\left(\nabla^{2} \psi\right)}{\partial x}-\frac{\partial \psi}{\partial x} \frac{\partial\left(\nabla^{2} \psi\right)}{\partial y} \\
& =\nu \nabla^{4} \psi-\left(\frac{\sigma \mu_{e}^{2} H_{o}^{2}}{\rho_{o}}\right) \frac{\partial^{2} \psi}{\partial y^{2}}-\left(\frac{\mu}{k}\right) \nabla^{2} \psi+ \\
& +\beta g \frac{\partial}{\partial y}\left(T-T_{1}\right)+\beta^{\bullet} g \frac{\partial}{\partial y}\left(C-C_{1}\right)
\end{aligned}
$$

The equations of energy and diffusion are

$$
\begin{aligned}
& \rho_{0} C_{p}\left(\frac{\partial T}{\partial t}+\frac{\partial \psi}{\partial y} \frac{\partial T}{\partial x}-\frac{\partial \psi}{\partial x} \frac{\partial T}{\partial y}\right) \\
& =k_{f}\left(\frac{\partial^{2} T}{\partial x^{2}}+\frac{\partial^{2} T}{\partial y^{2}}\right)+Q+\frac{16 \sigma^{\bullet} T_{e}^{3}}{3 \beta_{R}} \frac{\partial^{2} T}{\partial y^{2}} \\
& \left(\frac{\partial C}{\partial t}+\frac{\partial \psi}{\partial y} \frac{\partial C}{\partial x}-\frac{\partial \psi}{\partial x} \frac{\partial C}{\partial y}\right)=D_{1}\left(\frac{\partial^{2} C}{\partial x^{2}}+\frac{\partial^{2} C}{\partial y^{2}}\right)-K^{\prime} C
\end{aligned}
$$

On introducing the non-dimensional variables

$$
\begin{aligned}
u^{\prime} & =u /(v / L),\left(x^{\prime}, y^{\prime}\right)=(x, y) / L \\
\theta & =\frac{T-T_{1}}{T_{2}-T_{1}}, C^{\prime}=\frac{C-C_{1}}{C_{2}-C_{1}} \quad, \mathrm{t}^{\prime}=\omega \mathrm{t},
\end{aligned}
$$

The governing equations are in the non-dimensional form are

$$
\begin{array}{r}
\gamma^{2} \frac{\partial\left(\nabla^{2} \psi\right)}{\partial t}+\alpha_{1}\left(\frac{\partial \psi}{\partial y} \frac{\partial\left(\nabla^{2} \psi\right)}{\partial x}-\frac{\partial \psi}{\partial x} \frac{\partial\left(\nabla^{2} \psi\right)}{\partial y}\right)=\nabla^{4} \psi- \\
-D^{-1} \nabla^{2} \psi-M^{2} \frac{\partial^{2} \psi}{\partial y^{2}}+G\left(\frac{\partial \theta}{\partial y}+N \frac{\partial C}{\partial y}\right)
\end{array}
$$

$P_{1}\left(\gamma^{2} \frac{\partial \theta}{\partial t}+\left(\frac{\partial \psi}{\partial y} \frac{\partial \theta}{\partial x}-\frac{\partial \psi}{\partial x} \frac{\partial \theta}{\partial y}\right)\right)=\left(N_{2} \frac{\partial^{2} \theta}{\partial x^{2}}+\frac{\partial^{2} \theta}{\partial y^{2}}\right)+\alpha_{1}$

$S c\left(\gamma^{2} \frac{\partial C}{\partial t}+\left(\frac{\partial \psi}{\partial y} \frac{\partial C}{\partial x}-\frac{\partial \psi}{\partial x} \frac{\partial C}{\partial y}\right)\right)=\left(\frac{\partial^{2} C}{\partial x^{2}}+\frac{\partial^{2} C}{\partial y^{2}}\right)-(K S c) C$

where $\quad G=\beta_{0} g L^{3} \frac{\left(T_{2}-T_{1}\right)}{\gamma^{2}}$ (Grashof number),

$M^{2}=\frac{\sigma \mu_{e}^{2} H_{o}^{2} L^{2}}{v^{2}}$ (Hartmann Number)

$D^{-1}=\frac{L^{2}}{k}$ (Darcy parameter), $P=\frac{\mu C_{P}}{K_{f}}$ (Prandtl

number), $\alpha=\frac{Q \cdot \Delta T L^{2}}{K_{f}}$ (Heat source

parameter), $N=\frac{\beta^{\bullet}\left(C_{2}-C_{1}\right)}{\beta\left(T_{2}-T_{1}\right)}$ (Buoyancy ratio)

$S c=\frac{v}{D_{1}}$ (Schmidt number), $\gamma^{2}=\frac{\omega L^{2}}{v}$ (Womersley

Number)

$K=\frac{K^{\prime} L^{2}}{v}$ (Chemical reaction parameter),

$M_{1}^{2}=M^{2}+D^{-1}$

The transformed boundary conditions are

$$
\begin{array}{cc}
\mathrm{u}=0, \mathrm{v}=0, & \theta=0, \quad \mathrm{C}=0 \\
\mathrm{y}=-\mathrm{f}(\delta \mathrm{x}) & \\
\mathrm{u}=0, \mathrm{v}=0, & \theta=1+\in \cos (\omega \mathrm{t}), \mathrm{C}=1+\in \cos (\omega \mathrm{t}) \\
\text { at } \mathrm{y}=+\mathrm{f}(\delta \mathrm{x}) & (16)
\end{array}
$$

\section{SOLUTION OF THE PROBLEM}

On introducing the transformations

$$
\delta x=\bar{x} \text { and } \eta=\frac{y}{f(\bar{x})}
$$

the equations (12)-(14) reduce to

$$
\begin{array}{r}
\left(\gamma^{2} f^{2}\right) \frac{\partial\left(F^{2} \psi\right)}{\partial t}+\left(\alpha_{1} f\right) \\
\left(\frac{\partial \psi}{\partial \eta} \frac{\partial\left(F^{2} \psi\right)}{\partial x}-\frac{\partial \psi}{\partial x} \frac{\partial\left(F^{2} \psi\right)}{\partial \eta}\right)=F^{4} \psi- \\
\left.-\left(M_{1}^{2} f^{2}\right) \frac{\partial^{2} \psi}{\partial \eta^{2}}+G f^{3}\right)\left(\frac{\partial \theta}{\partial \eta}+N \frac{\partial C}{\partial \eta}\right)
\end{array}
$$

$$
\begin{aligned}
& P_{1}\left(\gamma^{2} f^{2} \frac{\partial \theta}{\partial t}+\delta f\left(\frac{\partial \psi}{\partial \eta} \frac{\partial \theta}{\partial x}-\frac{\partial \psi}{\partial x} \frac{\partial \theta}{\partial \eta}\right)\right) \\
& =\left(\delta^{2} N_{2} \frac{\partial^{2} \theta}{\partial x^{2}}+\frac{\partial^{2} \theta}{\partial \eta^{2}}\right)+\alpha_{1} f^{2}
\end{aligned}
$$




\section{Available online at www.ijrat.org}

$S c\left(\gamma^{2} f^{2} \frac{\partial C}{\partial t}+\delta f\left(\frac{\partial \psi}{\partial \eta} \frac{\partial C}{\partial x}-\frac{\partial \psi}{\partial x} \frac{\partial C}{\partial \eta}\right)\right)$

$=\left(\delta^{2} \frac{\partial^{2} C}{\partial x^{2}}+\frac{\partial^{2} C}{\partial \eta^{2}}\right)-\left(K S c f^{2}\right) C$

In view of the boundary conditions (15-16) we assume

$\psi(x, \eta, t)=\psi_{0}(x, \eta)+\varepsilon e^{i t} \psi_{1}(x, \eta)+$

$$
\theta(x, \eta, t)=\theta_{0}(x, \eta)+\varepsilon e^{i t} \theta_{1}(x, \eta)+
$$

$C(x, \eta, t)=C_{0}(x, \eta)+\varepsilon e^{i t} C_{1}(x, \eta)+$

Substituting the series expansion (21) in equations (17)-(20) and separating the steady and transient terms we get

$$
\begin{gathered}
\left(\alpha_{1} \delta\right)\left(\frac{\partial \psi_{0}}{\partial \eta} \frac{\partial^{3} \psi_{0}}{\partial \eta^{2} \partial x}-\frac{\partial \psi_{0}}{\partial x} \frac{\partial^{3} \psi_{0}}{\partial \eta^{3}}\right)=\frac{\partial^{4} \psi_{0}}{\partial \eta^{4}}-M_{1}^{2} \frac{\partial^{2} \psi_{0}}{\partial \eta^{2}}+ \\
+\left(G f^{3}\right)\left(\frac{\partial \theta_{0}}{\partial \eta}+N \frac{\partial C_{0}}{\partial \eta}\right)
\end{gathered}
$$

$\left(i \gamma^{2} f^{2}\right) \frac{\partial^{2} \psi_{1}}{\partial \eta^{2}}+(\delta f)\left(\frac{\partial \psi_{1}}{\partial \eta} \frac{\partial^{3} \psi_{0}}{\partial \eta^{2} \partial x}+\frac{\partial \psi_{1}}{\partial \eta} \frac{\partial^{3} \psi_{0}}{\partial \eta^{2} \partial x}-\frac{\partial \psi_{1}}{\partial x} \frac{\partial^{3} \psi_{0}}{\partial \eta^{3}}-\right.$

$$
\left.-\frac{\partial \psi_{0}}{\partial x} \frac{\partial^{3} \psi_{1}}{\partial \eta^{3}}\right)=\frac{\partial^{4} \psi_{1}}{\partial \eta^{4}}-M_{1}^{2} \frac{\partial^{2} \psi_{0}}{\partial \eta^{2}}+\left(G f^{3}\right)\left(\frac{\partial \theta_{1}}{\partial \eta}+N \frac{\partial C_{1}}{\partial \eta}\right)
$$

$\left(P_{1} \delta f\right)\left(\frac{\partial \psi_{0}}{\partial \eta} \frac{\partial \theta_{0}}{\partial x}-\frac{\partial \psi_{0}}{\partial x} \frac{\partial \theta_{0}}{\partial \eta}\right)=\frac{\partial^{2} \theta_{0}}{\partial \eta^{2}}+\alpha_{1} f^{2}$

$P_{1}\left(i \gamma^{2} \theta_{1}+(\delta f)\left(\frac{\partial \psi_{1}}{\partial \eta} \frac{\partial \theta_{0}}{\partial x}+\frac{\partial \theta_{1}}{\partial x} \frac{\partial \psi_{0}}{\partial \eta}-\frac{\partial \psi_{0}}{\partial x} \frac{\partial \theta_{1}}{\partial \eta}-\right.\right.$

$$
\left.-\frac{\partial \theta_{0}}{\partial \eta} \frac{\partial \psi_{1}}{\partial x}\right)=\frac{\partial^{2} \theta_{1}}{\partial \eta^{2}}
$$

$$
\begin{gathered}
\frac{\partial^{2} C_{0}}{\partial \eta^{2}}-\left(K f^{2} S c\right) C_{0}=0 \\
\frac{\partial^{2} C_{1}}{\partial \eta^{2}}-\left(f^{2} S c\left(k+i \gamma^{2}\right) C_{1}=(\delta S c f)\left(\frac{\partial \psi_{1}}{\partial \eta} \frac{\partial c_{0}}{\partial x}+\right.\right. \\
\left.+\frac{\partial C_{1}}{\partial x} \frac{\partial \psi_{0}}{\partial \eta}-\frac{\partial \psi_{0}}{\partial x} \frac{\partial C_{1}}{\partial \eta}-\frac{\partial C_{0}}{\partial \eta} \frac{\partial \psi_{1}}{\partial x}\right)
\end{gathered}
$$

The equations (22-27) are non-linear in nature. Assuming $\delta<<1$ we take the solutions as

$$
\begin{aligned}
& \psi_{0}=\psi_{00}+\delta \psi_{01}+\ldots \\
& \psi_{1}=\psi_{10}+\delta \psi_{11}+\ldots \\
& \theta_{0}=\theta_{00}+\delta \theta_{01}+\ldots \\
& \theta_{1}=\theta_{10}+\delta \theta_{11}+\ldots \\
& C_{0}=C_{00}+\delta C_{01}+\ldots \\
& C_{1}=C_{10}+\delta C_{11}+\ldots
\end{aligned}
$$

$$
\begin{aligned}
& \frac{d^{2} C_{00}}{d \eta^{2}}-\beta_{1}^{2} C_{00}=0, C_{00}(-1)=0, C_{00}(+1)=1(29) \\
& \frac{d^{2} \theta_{00}}{d \eta^{2}}=-\alpha_{1} f^{2}-N_{2} Q_{1} C_{00}, \theta_{00}(-1)=0, \theta_{00}(+1)=1
\end{aligned}
$$

$$
\frac{d^{2} C_{01}}{d \eta^{2}}-\beta_{1}^{2} C_{01}=0, C_{01}(-1)=0, C_{01}(+1)=0
$$

$\frac{d^{2} \theta_{01}}{d \eta^{2}}=-Q_{1} C_{01}, \theta_{01}(-1)=0, \theta_{01}(+1)=0$

$\frac{d^{4} \psi_{00}}{d \eta^{4}}-M_{1}^{2} \frac{d^{2} \psi_{00}}{d \eta^{2}}-G f^{3}\left(\frac{d \theta_{00}}{d \eta}+N \frac{d C_{00}}{d \eta}\right)$,

$\psi_{00}(+1)-\psi_{00}(-1)=1, \frac{d \psi_{00}}{d \eta}=0, \frac{d \psi_{00}}{d x}=0$

$\frac{d^{4} \psi_{01}}{d \eta^{4}}-M_{1}^{2} \frac{d^{2} \psi_{01}}{d \eta^{2}}-G f^{3}\left(\frac{d \theta_{01}}{d \eta}+N \frac{d C_{01}}{d \eta}\right)$

$+\left(\alpha_{1} f\right)\left(\frac{d \psi_{00}}{d \eta} \frac{d^{3} \psi_{00}}{d \eta^{2} d x}-\frac{d \psi_{00}}{d x} \frac{d^{3} \psi_{00}}{d \eta^{3}}\right)+$

$\psi_{01}(+1)-\psi_{01}(-1)=0, \frac{d \psi_{01}}{d \eta}=0, \frac{d \psi_{01}}{d x}=0$

$\frac{d^{2} C_{10}}{d \eta^{2}}-\beta_{5}^{2} C_{10}=0, C_{10}(-1)=0, C_{10}(+1)=1$

$\frac{d^{2} \theta_{11}}{d \eta^{2}}-\beta_{6}^{2} \theta_{10}=-Q_{1} C_{10}, \theta_{10}(-1)=0, \theta_{10}(+1)=1$

$\frac{d^{2} C_{11}}{d \eta^{2}}-\beta_{8}^{2} C_{11}=\left(\alpha_{1} f\right)\left(\frac{d \psi_{00}}{d \eta} \frac{d C_{10}}{d x}\right.$

$\left.+\frac{d \psi_{10}}{d \eta} \frac{d C_{00}}{d x}-\frac{d \psi_{00}}{d x} \frac{d C_{10}}{d \eta}-\frac{d \psi_{10}}{d x} \frac{d C_{00}}{d \eta}\right)$,

$$
C_{11}(-1)=0, C_{11}(+1)=0
$$

$\frac{d^{2} \theta_{11}}{d \eta^{2}}-\beta_{6}^{2} \theta_{11}=-\left(Q_{1} f^{2}\right) C_{11}+\left(\alpha_{1} f\right)\left(\frac{d \psi_{00}}{d \eta} \frac{d \theta_{10}}{d x}\right.$

$\left.+\frac{d \psi_{10}}{d \eta} \frac{d \theta_{00}}{d x}-\frac{d \psi_{00}}{d x} \frac{d \theta_{10}}{d \eta}-\frac{d \psi_{10}}{d x} \frac{d \theta_{00}}{d \eta}\right)$,

$\theta_{11}(-1)=0, \theta_{11}(+1)=0$

$$
\begin{array}{r}
\frac{d^{4} \psi_{10}}{d \eta^{4}}-\beta_{7}^{2} \frac{d^{2} \psi_{10}}{d \eta^{2}}-G f^{3}\left(\frac{d \theta_{10}}{d \eta}+N \frac{d C_{10}}{d \eta}\right) \\
\psi_{10}(+1)-\psi_{10}(-1)=0, \frac{d \psi_{10}}{d \eta}=0, \frac{d \psi_{10}}{d x}=0
\end{array}
$$

Substituting (28) in equations (22)-(27) and separating the like powers of $\delta$ we obtain 


$$
\begin{aligned}
& \frac{d^{4} \psi_{11}}{d \eta^{4}}-\beta_{7}^{2} \frac{d^{2} \psi_{11}}{d \eta^{2}}-G f^{3}\left(\frac{d \theta_{11}}{d \eta}+N \frac{d C_{11}}{d \eta}\right) \\
& +\left(\alpha_{1} f\right)\left(\frac{d \psi_{00}}{d \eta} \frac{d^{3} \psi_{10}}{d \eta^{2} d x}-\frac{d \psi_{00}}{d x} \frac{d^{3} \psi_{10}}{d \eta^{3}}\right)+ \\
& \psi_{11}(+1)-\psi_{11}(-1)=0, \frac{d \psi_{11}}{d \eta}=0, \frac{d \psi_{11}}{d x}=0
\end{aligned}
$$

On solving the equations (29)-(40) subject to relevant boundary conditions we obtain

$$
\begin{aligned}
& C_{00}=0.5\left(\frac{C h\left(\beta_{1} \eta\right)}{C h\left(\beta_{1}\right)}+\frac{\operatorname{Sh}\left(\beta_{1} \eta\right)}{\operatorname{Sh}\left(\beta_{1}\right)}\right) \\
& \theta_{00}=a_{3}\left(1-\eta^{2}\right)+a_{4}\left(C h\left(\beta_{1}\right)-C h\left(\beta_{1} \eta\right)\right) \\
& +a_{5}\left(\eta \operatorname{Sh}\left(\beta_{1}\right)-\operatorname{Sh}\left(\beta_{1} \eta\right)\right) \\
& \psi_{00}=a_{15} \operatorname{Ch}\left(\beta_{2} \eta\right)+a_{16} \operatorname{Sh}\left(\beta_{2} \eta\right)+a_{17} \eta+a_{18}+\phi_{1}(\eta) \\
& \phi_{1}(\eta)=a_{11}-a_{12} \eta+a_{13} \operatorname{Sh}\left(\beta_{1} \eta\right)+a_{14} C h\left(\beta_{1} \eta\right) \\
& C_{01}=0 \\
& \theta_{01}=0 \\
& C_{10}=0.5\left(\frac{C h\left(\beta_{5} \eta\right)}{C h\left(\beta_{5}\right)}+\frac{\operatorname{Sh}\left(\beta_{5} \eta\right)}{\operatorname{Sh}\left(\beta_{5}\right)}\right) \\
& \theta_{10}=0.5\left(\frac{C h\left(\beta_{6} \eta\right)}{C h\left(\beta_{6}\right)}+\frac{\operatorname{Sh}\left(\beta_{6} \eta\right)}{\operatorname{Sh}\left(\beta_{6}\right)}\right) \\
& \psi_{10}=b_{29} C h\left(\beta_{7} \eta\right)+b_{30} \operatorname{Sh}\left(\beta_{7} \eta\right)+\phi_{3}(\eta) \\
& \phi_{3}(\eta)=-\left(b_{33} \operatorname{Sh}\left(\beta_{5} \eta\right)+b_{34} C h\left(\beta_{5} \eta\right)\right. \\
& +b_{35} \operatorname{Sh}\left(\beta_{6} \eta\right)+b_{37} C h\left(\beta_{6} \eta\right) \\
& C_{11}=e_{1} \operatorname{Ch}\left(\beta_{8} \eta\right)+e_{2} \operatorname{Sh}\left(\beta_{8} \eta\right)+\phi_{4}(\eta) \\
& \phi_{4}(\eta)=d_{13} \eta^{2}-\left(d_{75}-\eta d_{17}\right) \operatorname{Sh}\left(\beta_{1} \eta\right) \\
& -\left(d_{76}-\eta d_{19}\right) C h\left(\beta_{1} \eta\right)
\end{aligned}
$$$$
-d_{20} \operatorname{Sh}\left(2 \beta_{1} \eta\right)--d_{21} \operatorname{Ch}\left(2 \beta_{1} \eta\right)-\left(d_{77}+\eta d_{25}\right) \operatorname{Sh}\left(\beta_{5} \eta\right)
$$$$
-\left(d_{78}-\eta d_{27}\right) \operatorname{Ch}\left(\beta_{5} \eta\right)++\left(d_{29}+\eta d_{83}\right) \operatorname{Sh}\left(\beta_{8} \eta\right)
$$$$
+\left(d_{80}+\eta d_{36}\right) \operatorname{Sh}\left(\beta_{9} \eta\right)+\left(d_{81}+\eta d_{38}\right) \operatorname{Ch}\left(\beta_{8} \eta\right)
$$$$
+\left(d_{82}+\eta d_{40}\right) \operatorname{Ch}\left(\beta_{9} \eta\right)+d_{84} \operatorname{Sh}\left(\beta_{10} \eta\right)
$$$$
+\left(d_{85}+\eta d_{43}\right) \operatorname{Sh}\left(\beta_{11} \eta\right)+\left(d_{86}+\right.
$$$$
\left.+\eta d_{56}\right) \operatorname{Ch}\left(\beta_{11} \eta\right)+\left(d_{45}+\eta d_{48}\right) \operatorname{Ch}\left(\beta_{10} \eta\right)
$$$$
+\left(d_{87}+\eta d_{56}\right) \operatorname{Ch}\left(\beta_{12} \eta\right)+\left(d_{88}\right.
$$$$
\left.+\eta d_{52}\right) \operatorname{Sh}\left(\beta_{12} \eta\right)+d_{89} \operatorname{Ch}\left(\beta_{13} \eta\right)+\left(d_{61}+\eta d_{90}\right) \operatorname{Sh}\left(\beta_{13} \eta\right)
$$$$
+\left(d_{91}+\eta d_{94}\right) x
$$$$
x \operatorname{Sh}\left(\beta_{14} \eta\right)+\left(d_{92}+\eta d_{93}\right) \operatorname{Ch}\left(\beta_{14} \eta\right)
$$$$
+\left(d_{94}+\eta d_{66}\right) \operatorname{Ch}\left(\beta_{15} \eta\right)+\left(d_{93}+\eta d_{72}\right) x
$$$$
x \operatorname{Sh}\left(\beta_{15} \eta\right)
$$

$$
\theta_{11}=f_{68} \operatorname{Ch}\left(\beta_{6} \eta\right)+f_{69} \operatorname{Sh}\left(\beta_{6} \eta\right)+\phi_{5}(\eta)
$$$$
\phi_{5}(\eta)=f_{1}+f_{2} \eta+f_{3} \eta^{2}+\left(f_{4}+\eta^{2} f_{6}\right) C h\left(\beta_{1} \eta\right)
$$$$
+\left(f_{5}+\eta^{2} f_{7}\right) \operatorname{Sh}\left(\beta_{1} \eta\right)+\left(f_{8}-\eta f_{12}-\right.
$$$$
\left.-\eta^{2} f_{13}+\eta^{4} f_{14}\right) \operatorname{Sh}\left(\beta_{5} \eta\right)
$$$$
+\left(f_{9}+\eta^{2} f_{10}-\eta^{3} f_{15}\right) C h\left(\beta_{5} \eta\right)+\left(f_{16} \eta+\eta^{3} f_{18}\right) x
$$$$
x \operatorname{Ch}\left(\beta_{6} \eta\right)+\eta f_{17} \operatorname{Sh}\left(\beta_{6} \eta\right)
$$

$+\left(f_{21}+\eta^{2} f_{24}-\eta^{3} f_{25}\right) C h\left(\beta_{7} \eta\right)-\left(\eta f_{22}+\eta^{3} f_{26}\right) x$ $x \operatorname{Sh}\left(\beta_{7} \eta\right)-\left(f_{27}-\eta^{2} f_{31}\right) \operatorname{Sh}\left(\beta_{8} \eta\right)$

$+f_{28} C h\left(\beta_{9} \eta\right)+\left(f_{29}+\eta^{2} f_{32}\right) \operatorname{Ch}\left(\beta_{8} \eta\right)+$

$-\left(f_{30}-\eta^{2} f_{34}\right) \operatorname{Sh}\left(\beta_{9} \eta\right)+\left(f_{35}+\eta^{2} f_{37}\right) \operatorname{Sh}\left(\beta_{10} \eta\right)$

$+\left(f_{36}+\eta^{2} f_{40}\right) \operatorname{Ch}\left(\beta_{11} \eta\right)+$

$+\left(f_{39}+\eta^{2} f_{41}\right) \operatorname{Sh}\left(\beta_{11} \eta\right)+\left(f_{42}+\eta^{2} f_{43}\right) \operatorname{Sh}\left(\beta_{12} \eta\right)$

$x \operatorname{Ch}\left(\beta_{22} \eta\right)+\left(f_{66}+\eta f_{67}\right) \operatorname{Sh}\left(2 \beta_{1} \eta\right)$

$+\left(f_{44}+\eta^{2} f_{46}\right) \operatorname{Sh}\left(\beta_{13} \eta\right)+$

$+\left(f_{47} \eta^{2}\right) \operatorname{Ch}\left(\beta_{13} \eta\right)+\left(f_{50}+\eta^{2} f_{51}\right) \operatorname{Ch}\left(\beta_{14} \eta\right)$

$+\left(f_{52}+\eta^{2} f_{53}\right) \operatorname{Sh}\left(\beta_{14} \eta\right)+\left(f_{54}+\right.$

$\left.+\eta^{2} f_{56}\right) C h\left(\beta_{15} \eta\right)+\left(f_{55}+\eta^{2} f_{57}\right) \operatorname{Sh}\left(\beta_{15} \eta\right)$

$+f_{58} \operatorname{Sh}\left(\beta_{22} \eta\right)+\left(f_{59}+\eta^{2} f_{64}\right) x$

$x \operatorname{Sh}\left(\beta_{23} \eta\right)+\left(f_{60}+\eta^{2} f_{63}\right) \operatorname{Sh}\left(\beta_{24} \eta\right)$

$+f_{61} C h\left(\beta_{23} \eta\right)+f_{62} C h\left(\beta_{24} \eta\right)+f_{65} \eta^{2} x$

where

$\beta_{1}^{2}=K S c f^{2} \quad \beta_{2}^{2}=M_{1}^{2} f^{2} \quad \beta_{3}=\beta_{1}+\beta_{2}$

$\beta_{4}=\beta_{1}-\beta_{2} \quad \beta_{5}^{2}=\left(i \gamma^{2}+K\right) S c f^{2} \beta_{6}^{2}=i \gamma^{2} P$

$\beta_{7}^{2}=\left(M_{1}^{2}+i \gamma^{2}\right) f^{2} \quad \beta_{8}=\beta_{1}+\beta_{5} \quad \beta_{9}=\beta_{1}-\beta_{5}$

$\beta_{12}=\beta_{1}+\beta_{6} \quad \beta_{13}=\beta_{1}-\beta_{6} \quad \beta_{14}=\beta_{1}+\beta_{7}$

$\beta_{15}=\beta_{1}-\beta_{7} \quad \beta_{16}=\beta_{2}+\beta_{5} \quad \beta_{17}=\beta_{2}-\beta_{5}$

$\beta_{19}=\beta_{1}+\beta_{8} \quad \beta_{20}=\beta_{1}-\beta_{8} \quad \beta_{21}=\beta_{1}+\beta_{9}$

$\beta_{22}=\beta_{1}-\beta_{9} \quad \beta_{23}=\beta_{2}+\beta_{6} \quad \beta_{24}=\beta_{2}-\beta_{6}$

and $\mathrm{a}_{1}, \mathrm{a}_{2}, \ldots, \mathrm{a}_{110}, \mathrm{~b}_{1}, \mathrm{~b}_{2}, \ldots \ldots, \mathrm{b}_{146}, \mathrm{f}_{1}, \mathrm{f}_{2}, \ldots . \mathrm{f}_{67}$ are constants.

\section{NUSSELT NUMBER and SHERWOOD NUMBER}

The Rate of heat transfer (Nusselt number )at $\eta= \pm 1$ is given by

$\mathrm{q}_{\mathrm{w}}=N u( \pm 1)=\left(\frac{1}{\theta_{m}-\theta_{w}}\right)\left(\frac{d \theta}{d y}\right)_{y= \pm 1}$ and the corresponding expressions are 


\section{Available online at www.ijrat.org}

$$
\begin{aligned}
& N u_{\eta=+1}=\frac{1}{\theta_{m}-1}\left(d_{1}+\varepsilon e^{i t} d_{3}\right), \\
& N u_{\eta=-1}=\frac{1}{\theta_{m}}\left(d_{2}+\varepsilon e^{i t} d_{4}\right), \\
& \theta_{m}=d_{5}+\varepsilon e^{i t} d_{6}
\end{aligned}
$$

The Rate of mass transfer (Sherwood Number) at $\eta= \pm 1$ is given by

$\operatorname{Sh}( \pm 1)=\left(\frac{1}{C_{m}-C_{w}}\right)\left(\frac{d C}{d \eta}\right)_{\eta= \pm 1}$ and the

corresponding expressions are

$$
\begin{aligned}
& S h_{\eta=+1}=\frac{1}{C_{m}-1}\left(d_{7}+\varepsilon e^{i t} d_{9}\right), \\
& S h_{\eta=-1}=\frac{1}{C_{m}}\left(d_{8}+\varepsilon e^{i t} d_{10}\right), \\
& C_{m}=d_{11}+\varepsilon e^{i t} d_{12} \\
& \text { where } \mathrm{d}_{1}, \mathrm{~d}_{2}, \ldots . . \mathrm{d}_{12} \text { are constants }
\end{aligned}
$$

\section{DISCUSSION OF THE NUMERICAL RESULTS:}

We investigate the effect of chemical reaction on the unsteady convective heat and mass transfer flow of a viscous electrically conducting fluid in a vertical wavy channel which are maintained at oscillatory temperature and concentration. The walls are taken at $\eta= \pm 1+\beta \exp \left(-x^{2}\right) . \quad \beta>0$ corresponds to dilation of the channel walls and $\beta<0$ represents constriction of the walls. We confine our attention to the case of $\beta<0$.

The axial velocity $(\mathrm{u})$ is exhibited in figs $1-10$ for different values of $\mathrm{G}, \mathrm{M}, \mathrm{D}^{-1}, \alpha, \beta, \gamma, \mathrm{k}, \mathrm{N}, \mathrm{Sc}$, and $\mathrm{x}$. The actual axial velocity is in the vertically downwards. Fig.1 represents $u$ with Grashof number 1 . The magnitude of $u$ enhances with increase in $\mathrm{G}>0$ and depreciates with $\mathrm{G}<0$ with maximum at $\eta=0$. Higher the magnetic force lesser $|\mathrm{u}|$ in the flow region (fig.2). The variation of $\mathrm{u}$ with Darcy parameter $\mathrm{D}^{-1}$ is shown in fig.3. It is found that lesser the permeability of the porous medium smaller the axial velocity in the left half and larger in the right half of the channel. An increase in the strength of the heat source enhances $|u|$ everywhere in the region (fig.4). The variation of $u$ with $\beta$ shows that greater the constriction of the channel walls smaller $|\mathrm{u}|$ in the region (fig.5). An increase in Womersley number $\gamma$ leads to an enhancement in $|\mathrm{u}|$ (fig.6). Also $|\mathrm{u}|$ enhances with increase in the chemical reaction parameter $\mathrm{k}$ (fig.7). When the molecular buoyancy force dominates over the thermal buoyancy force the axial velocity enhances when the buoyancy forces act in the same direction and for the forces acting in the opposite directions the velocity depreciates in the flow region (fig.8). The variation of $u$ with Schmidt number Sc shows that lesser the molecular diffusivity larger $|\mathrm{u}|$ (fig.9). Moving along the axial direction the velocity enhances with $\mathrm{x} \leq \pi$ and depreciates with higher $x \geq 2 \pi$ (fig. 10).

The secondary velocity (v) is exhibited in figs 11-20 for different parametric values. Fig. 11 represents $v$ with $\mathrm{G}$. It is found that $\mathrm{v}$ is towards the mid region in the right half and is towards the boundary in the left half. $|\mathrm{v}|$ enhances with increase in $|\mathrm{G}|$. Higher the Lorentz force smaller $|\mathrm{v}|$ in the entire flow region (fig.12). From fig.13 we find that lesser the permeability of the porous medium smaller the secondary velocity v. An increase $\alpha \leq 4$ depreciates $|\mathrm{v}|$ and enhances with $\alpha \geq 6$ (fig.14). Greater the constriction of the channel walls larger $|v|$ in the flow region (fig.15). From fig.16 we find that the secondary velocity experiences an enhancement with increase in $\gamma$. The variation of $\mathrm{V}$ with chemical reaction parameter $\mathrm{k}$ shows that $|\mathrm{v}|$ enhances with increase in $\mathrm{k}$ in the left half and in the right half $|\mathrm{v}|$ depreciates with $\mathrm{k} \leq 1.5$ and enhances with higher $\mathrm{k} \geq 2.5$ (fig.17). The variation of $v$ with $\mathrm{N}$ shows that $|\mathrm{v}|$ enhances with $\mathrm{N}>0$ and reduces with $|N|(<0)$ (fig.18). The variation of $v$ with Sc shows that $|\mathrm{v}|$ enhances with increase in Sc. Thus lesser the molecular diffusivity larger the magnitude of $\mathrm{v}$ everywhere in the flow region(fig.19). Moving along the axial direction the secondary velocity enhances with x(fig.20).

The non-dimensional temperature $(\theta)$ is shown in figs.21-30 for different parametric values. We follow the convention that the non dimensional temperature $(\theta)$ is positive or negative according as the actual temperature is greater / lesser than the T2. Fig. 21 represents $\theta$ with G. It is found that the actual temperature reduces with $G>0$ and enhances with $|\mathrm{G}|$ in the entire region. The actual temperature enhances with higher Lorentz force(fig.22). Fig. 23 represents the temperature with $\mathrm{D}^{-1}$. It is found that the actual temperature enhances in the left half and reduces in the right half of the channel. Also an increase in $\alpha$ leads to an enhancement in the actual temperature in the flow region(fig.24). Greater the constriction of the channel walls larger the temperature (fig.25). From fig. 26 we find that $\theta$ depreciates with increase in $\gamma$. An increase in $\mathrm{k}$ leads to a depreciation in the actual temperature (fig.27). The variation of $\theta$ with $\mathrm{N}$ shows that the actual temperature reduces with $\mathrm{N}>0$ and enhances with $|\mathrm{N}|$ (<0) (fig.28). Lesser the molecular diffusivity smaller the actual temperature in the flow region (fig.29). Moving along the axial direction the actual temperature experiences an enhancement everywhere in the region (fig.30). From fig.31 we observe that $\theta$ depreciates with increase in prandtl number Pr.

The non-dimensional concentration (C) is exhibited in figs.32-41 for different parametric values. We follow the convention that the non dimensional concentration is positive or negative according as the actual concentration is greater/lesser than $\mathrm{C}_{2}$. Fig.32 represents $\mathrm{C}$ with $\mathrm{G}$. It is found that the actual concentration reduces with increase in $G>0$ and enhances with $|\mathrm{G}|$. An increase $M$ or $\alpha$ reduces the actual concentration (fig. $33 \& 35$ ). Fig. 34 shows the variation of 
International Journal of Research in Advent Technology, Vol.7, No.2, February 2019

E-ISSN: 2321-9637

Available online at www.ijrat.org

$\mathrm{C}$ with $\mathrm{D}^{-1}$.It is found that the actual concentration enhances with increase in $\mathrm{D}^{-1}$. Greater the constriction of the channel walls higher the actual concentration in the entire flow region (fig.36). An increase in $\gamma$ reduces the actual concentration (fig.37). From fig.38 it follows that an increase in the chemical reaction parameter $\mathrm{k}$ reduces the actual concentration and enhances with higher $\mathrm{k} \geq 2.5$. When the molecular buoyancy force dominates over the thermal buoyancy force the actual concentration enhances irrespective of the directions of the buoyancy forces (fig.39). The variation of $\mathrm{C}$ with $\mathrm{Sc}$ shows that the actual concentration depreciates with lesser the molecular diffusivity (fig.40). Moving along the axial distance of the channel the actual concentration reduces within the entire flow region (fig.41). 
Available online at www.ijrat.org
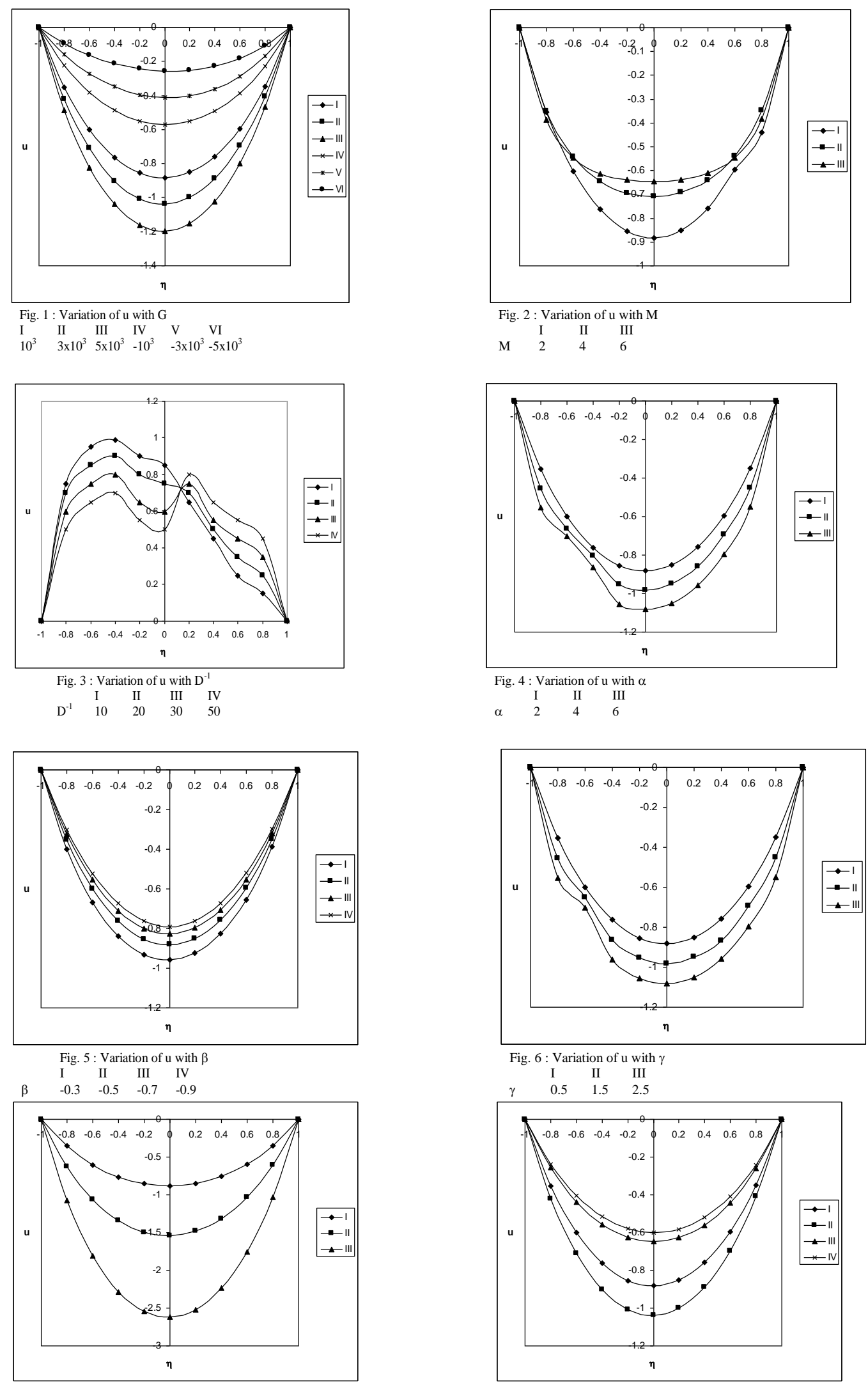

Fig. 7 : Variation of $\mathrm{u}$ with $\mathrm{k}$

$\begin{array}{llll} & \text { I } & \text { II } & \text { III } \\ \text { k } & 0.5 & 1.5 & 2.5\end{array}$

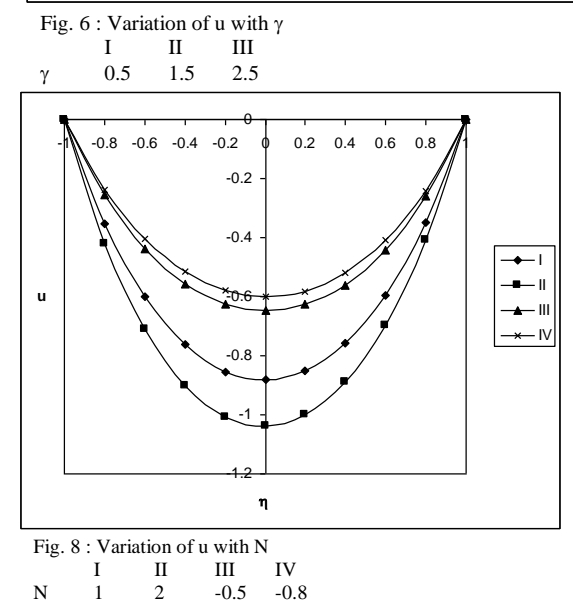


International Journal of Research in Advent Technology, Vol.7, No.2, February 2019

E-ISSN: 2321-9637

Available online at www.ijrat.org

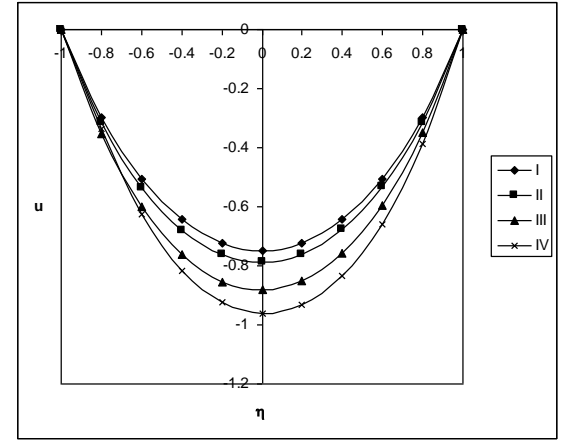

Fig. 9: Variation of $\mathrm{u}$ with $\mathrm{S}$
I II III IV

$\begin{array}{lllll} & \text { I } & \text { II } & \text { III } & \text { IV } \\ \text { Sc } & 0.24 & 0.6 & 1.3 & 2.01\end{array}$
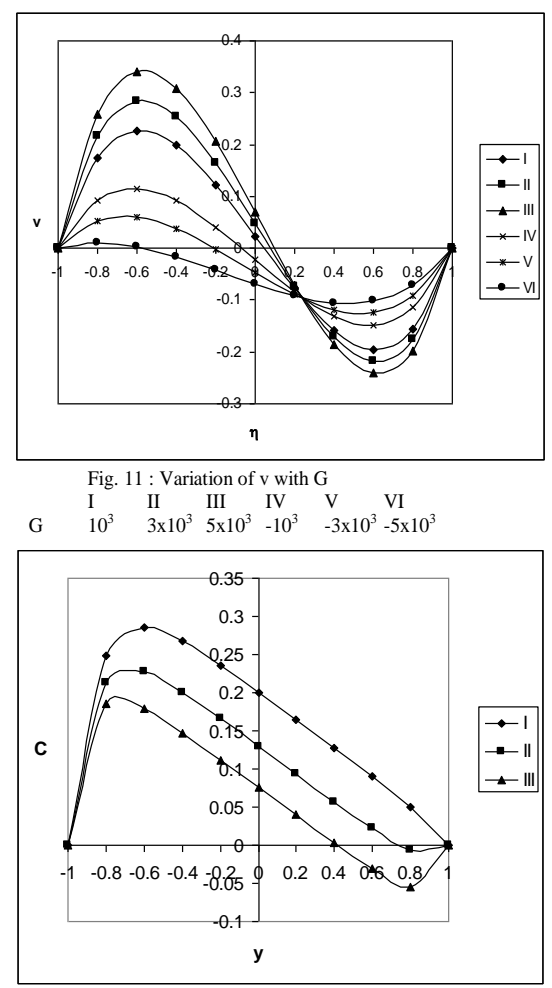

Fig 13 : Variation of $\mathrm{v}$ with $\mathrm{D}$

$\begin{array}{llll}\mathrm{D}^{-1} & 20 & 30 & 50\end{array}$

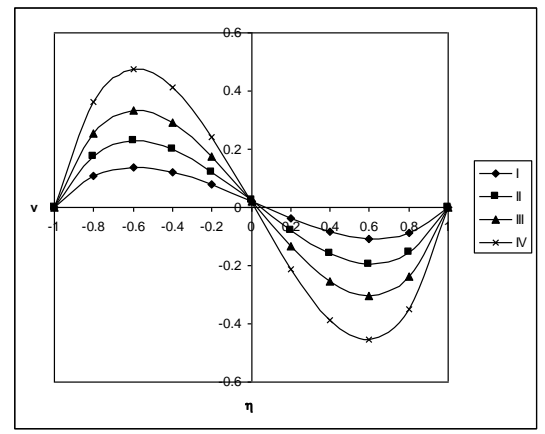

Fig. 15 : Variation of $\mathrm{v}$ with $\beta$

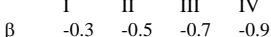

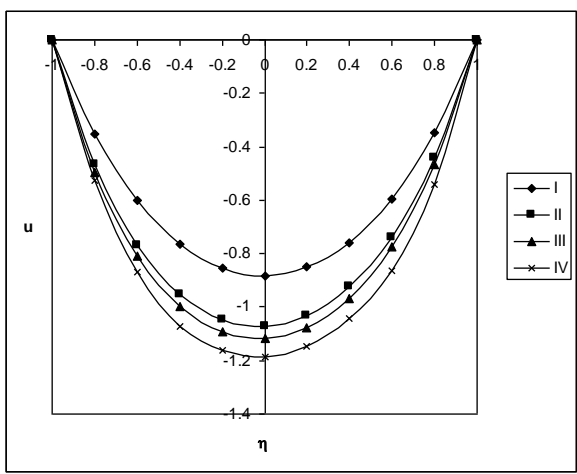

Fig. 10 : Variation of $\mathrm{u}$ with $\mathrm{x}$

$\begin{array}{llll}\text { I } & \text { II } & \text { III } & \text { IV } \\ \pi / 4 & \pi / 2 & \pi & 2 \pi\end{array}$

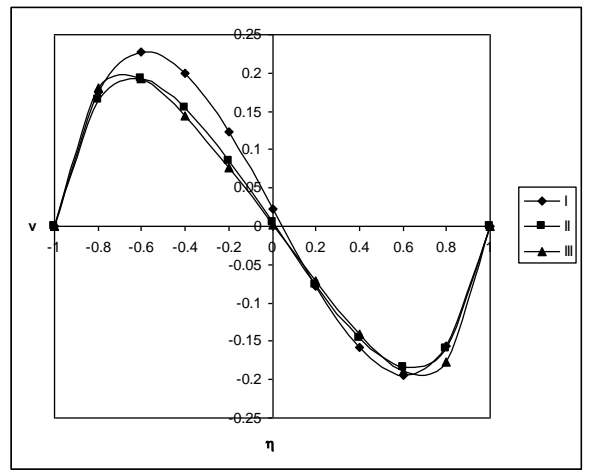

Fig. 12 : Variation of $\mathrm{v}$ with $\mathrm{M}$

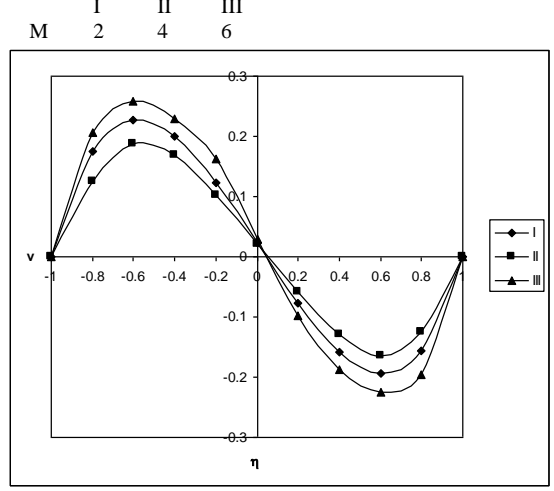

Fig. 14 : Variation of $\mathrm{v}$ with $\alpha$

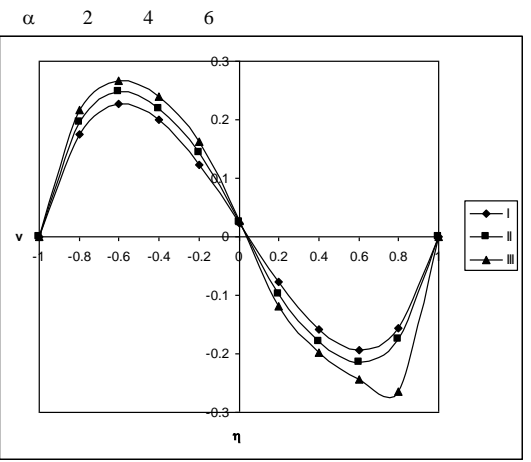

Fig. 16: Variation of $\mathrm{v}$ with $\gamma$

$\begin{array}{llll} & \text { I } & \text { II } & \text { III } \\ \gamma & 0.5 & 1.5 & 2.5\end{array}$ 
International Journal of Research in Advent Technology, Vol.7, No.2, February 2019

E-ISSN: 2321-9637

Available online at www.ijrat.org

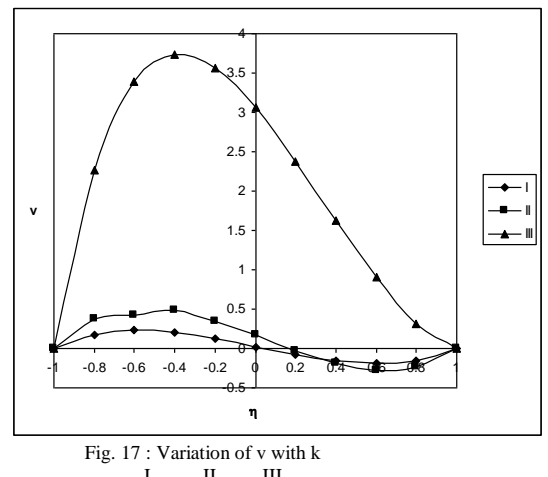

I II III

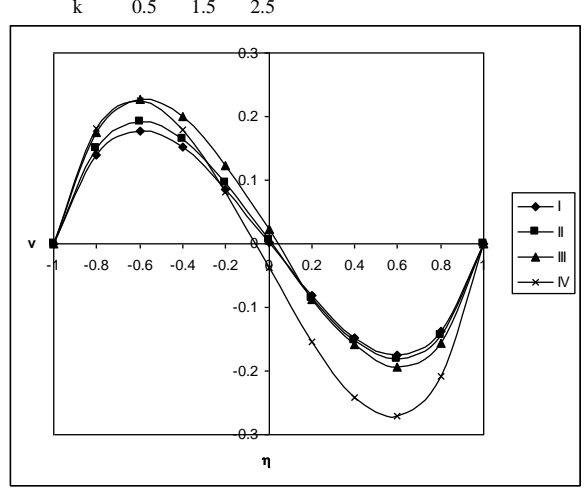

Fig. 19: Variation of v with Sc

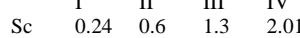

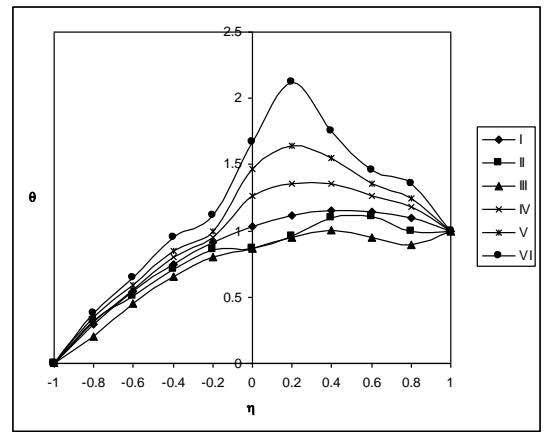

\begin{tabular}{lllllll}
\multicolumn{7}{c}{ Fig. 21 : Variation of $\theta$ with G } \\
& I & II & III & IV & V & VI \\
G & $10^{3}$ & $3 \times 10^{3}$ & $5 \times 10^{3}$ & $-10^{3}$ & $-3 \times 10^{3}$ & $-5 \times 10^{3}$
\end{tabular}

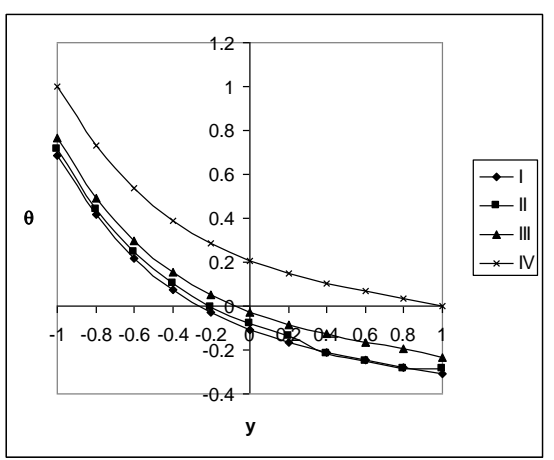

Fig 23 : Variation of $\theta$ with $\mathrm{D}^{-1}$

$\begin{array}{lllll} & \text { I } & \text { II } & \text { III } & \text { IV } \\ \mathrm{D}^{-1} & 10 & 20 & 30 & 50\end{array}$

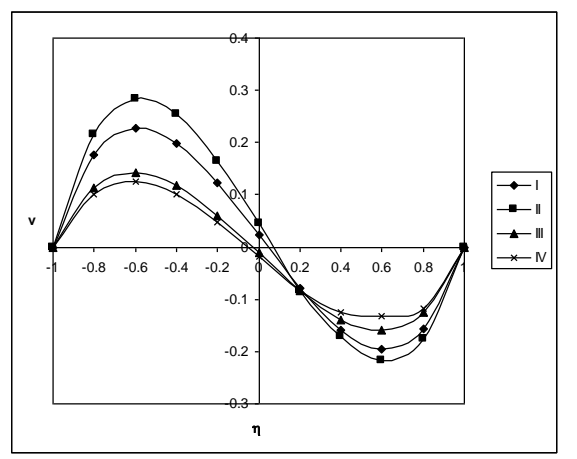

Fig. 18 : Variation of $\mathrm{v}$ with $\mathrm{N}$

$\begin{array}{lllll} & \text { I } & \text { II } & \text { III } & \text { IV } \\ \mathrm{N} & 1 & 2 & -0.5 & -0.8\end{array}$
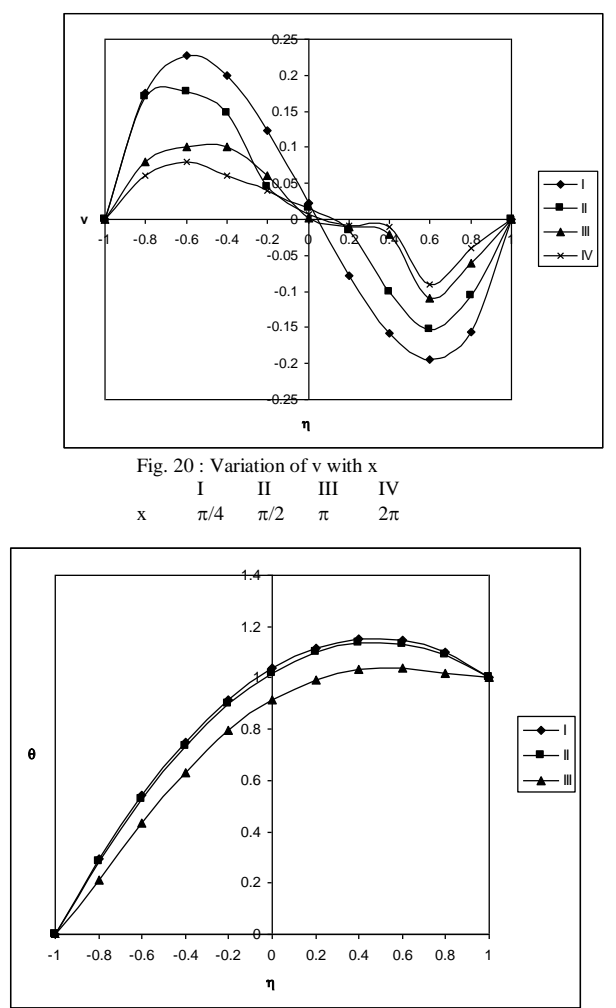

Fig. 22 : Variation of $\theta$ with $\mathrm{M}$

$\begin{array}{llll} & \text { I } & \text { II } & \text { III } \\ \text { M } & 2 & 4 & 6\end{array}$

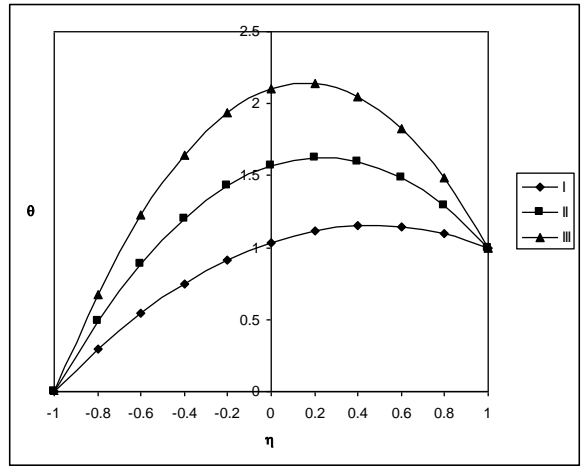

Fig. 24 : Variation of $\theta$ with $\alpha$

$\begin{array}{llll}1 & & & \end{array}$ 
Available online at www.ijrat.org
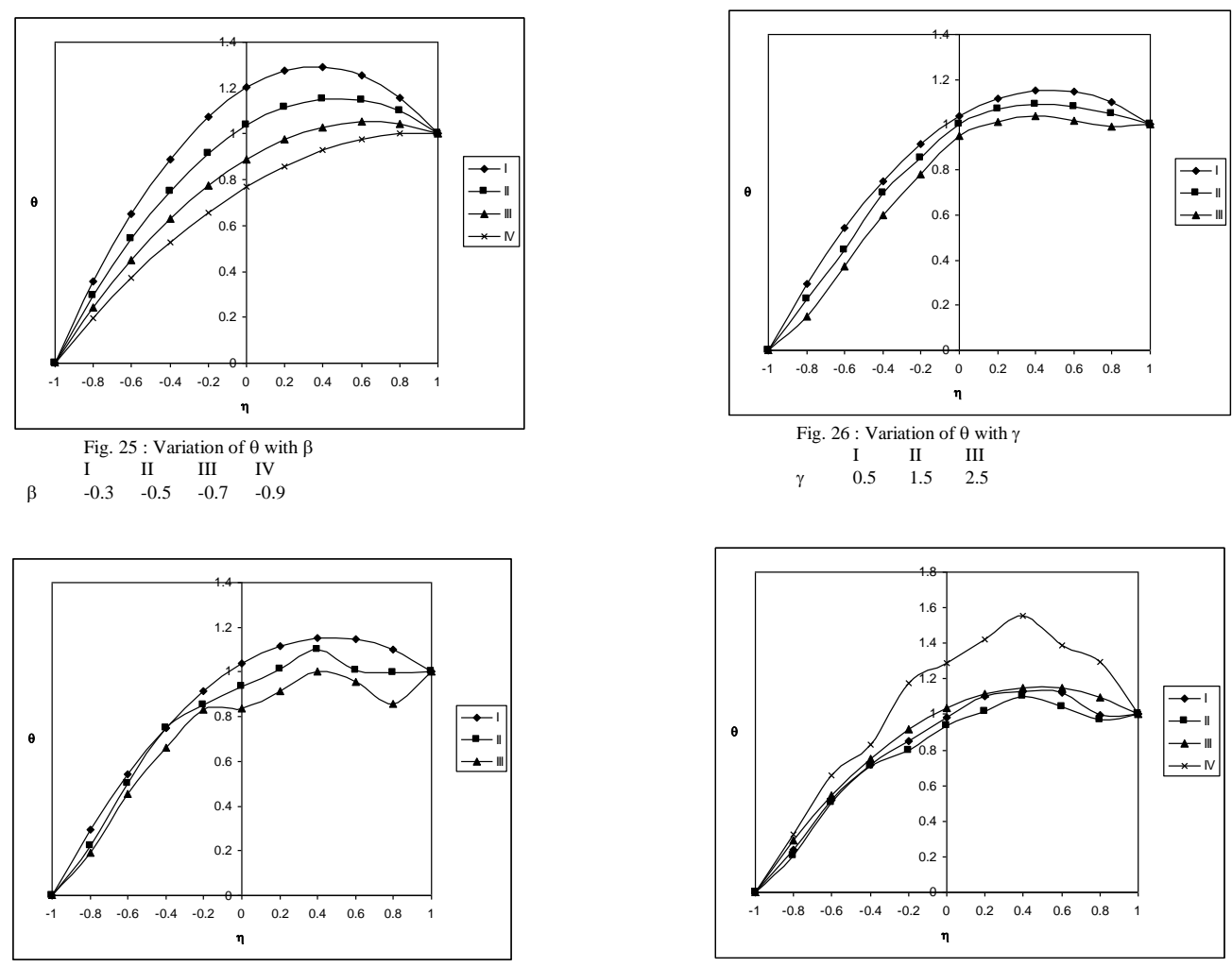

Fig. 27 : Variation of $\theta$ with
I II III
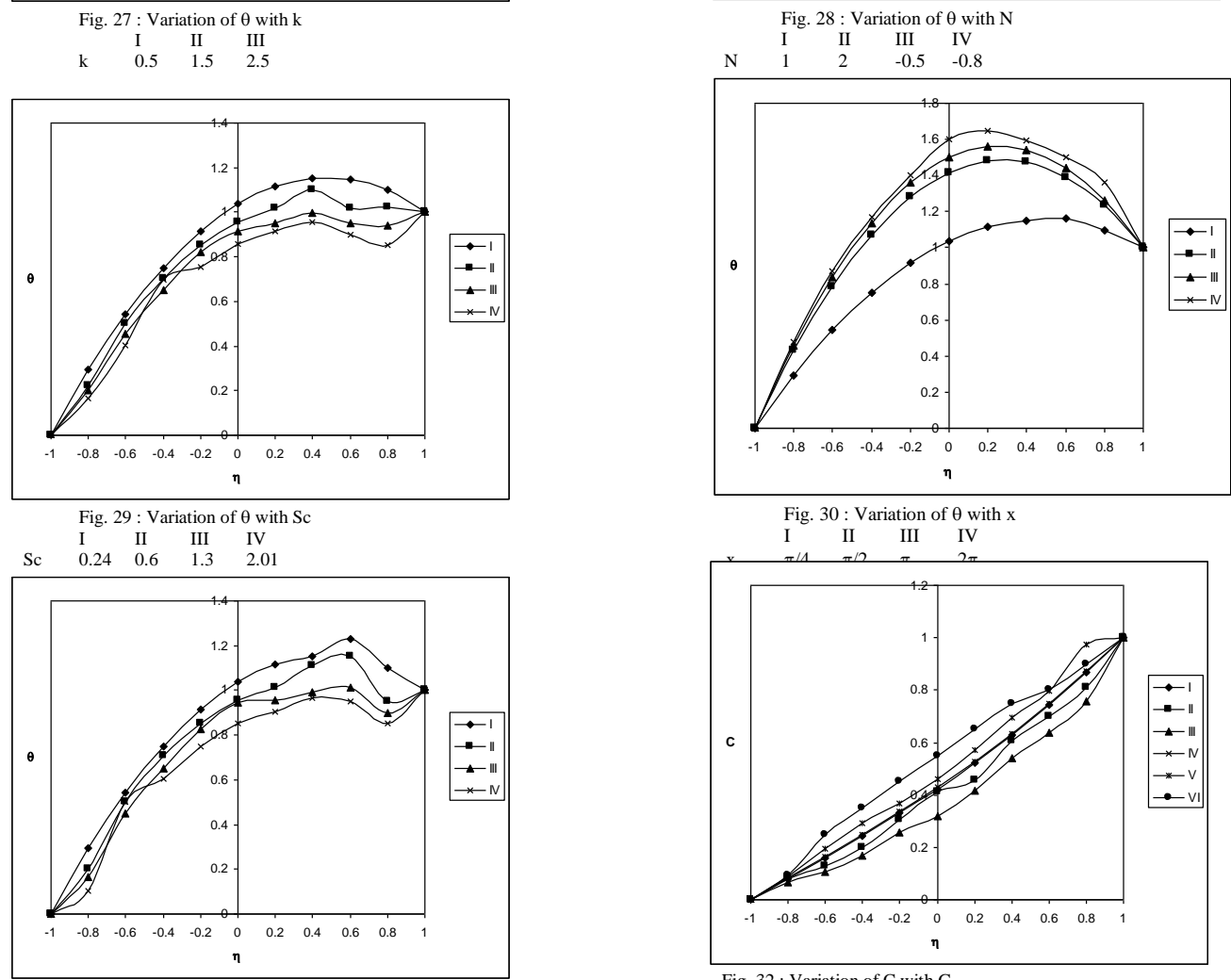

\begin{tabular}{ccccc} 
Fig. 31 : Variation of $\theta$ with $\mathrm{P}$ \\
\multicolumn{1}{c}{ II II } & II & IV \\
P & 0.71 & 7 & 10 & 30
\end{tabular}

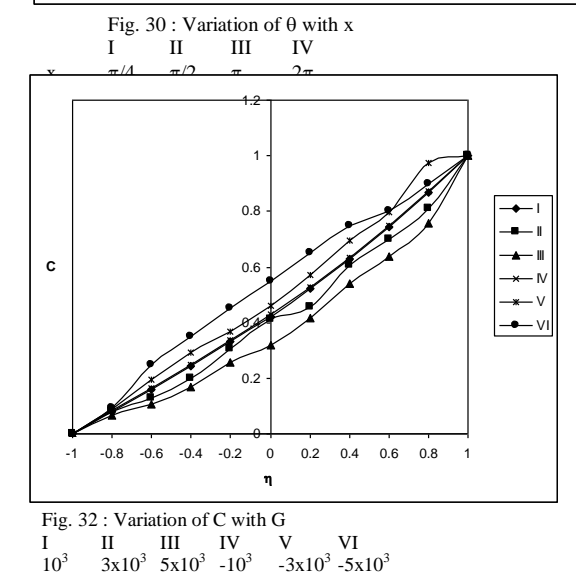


International Journal of Research in Advent Technology, Vol.7, No.2, February 2019 E-ISSN: 2321-9637

Available online at www.ijrat.org

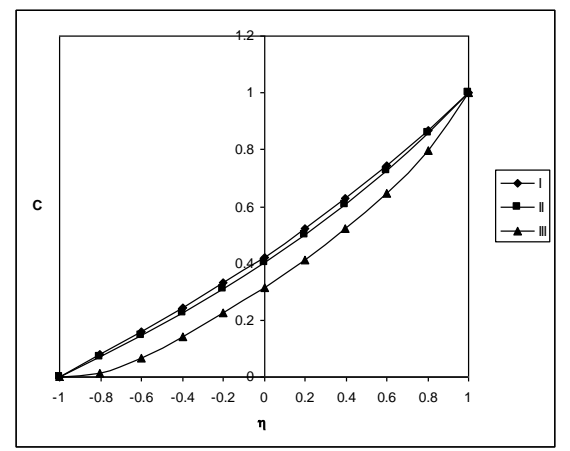

Fig. 33 : Variation of $\mathrm{C}$ with $\mathrm{M}$

$\begin{array}{llll} & \text { I } & \text { II } & \text { III } \\ \text { M } & 2 & 4 & 6\end{array}$

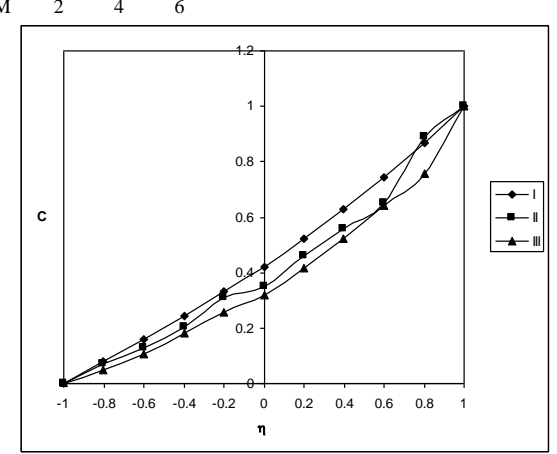

Fig. 35 : Variation of $\mathrm{C}$ with $\alpha$

$\begin{array}{llll} & \text { I } & \text { II } & \text { III } \\ \alpha & 2 & 4 & 6\end{array}$

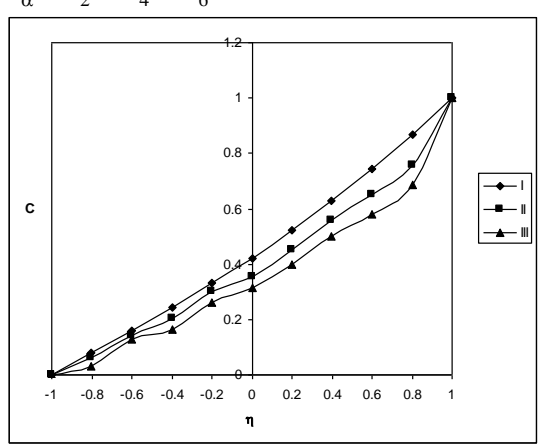

Fig. 37 : Variation of $\mathrm{C}$ with $\gamma$
I II III

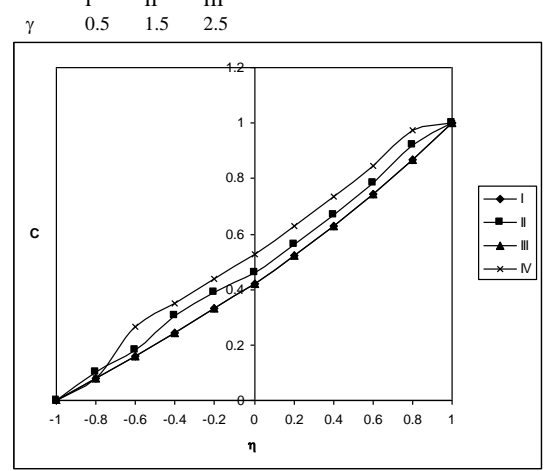

Fig. 39 : Variation of $\mathrm{C}$ with $\mathrm{N}$

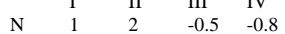

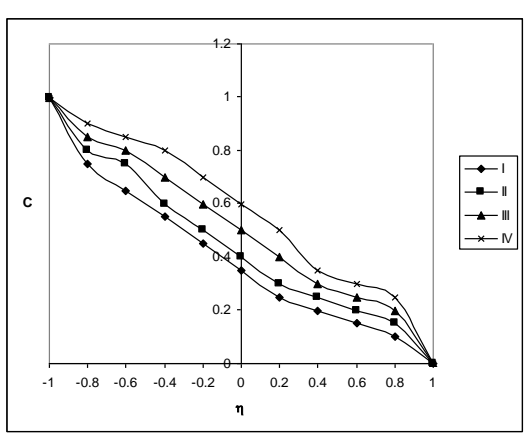

Fig 34 : Variation of $\mathrm{C}$ with $\mathrm{D}^{-1}$

$\begin{array}{llll}\mathrm{D}^{-1} & \text { I } & \text { II } & \text { III } \\ & 20 & 30 & 50\end{array}$

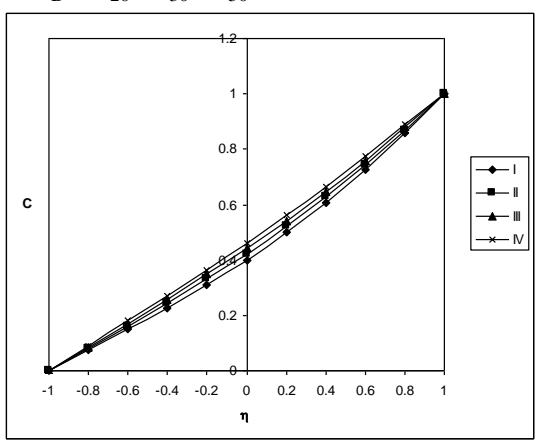

Fig. 36 : Variation of $\mathrm{C}$ with $\beta$
I II II II IV

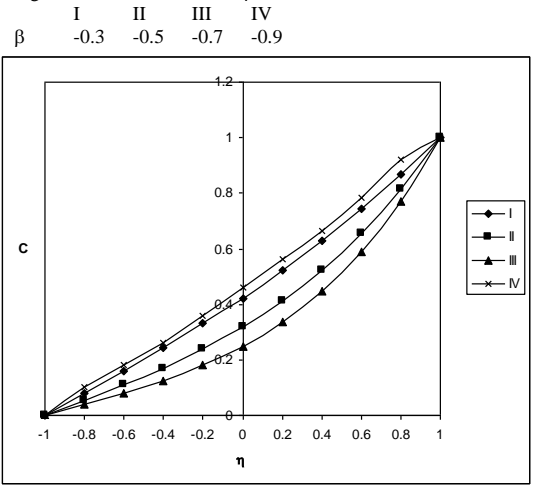

Fig. 38 : Variation of $\mathrm{C}$ with $\mathrm{k}$

$\begin{array}{llll}\text { k } & 0.5 & 1.5 & 2.5\end{array}$

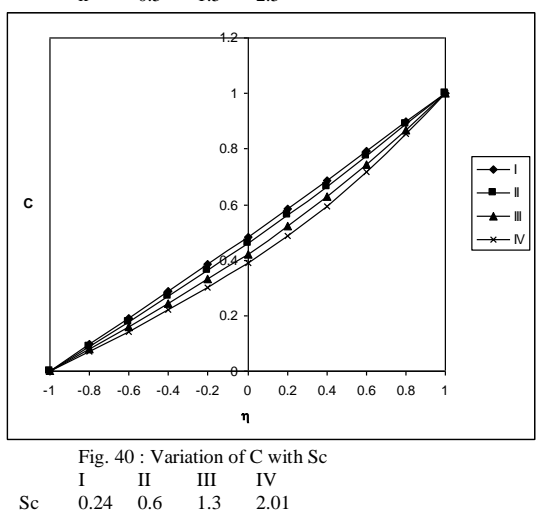




\section{Available online at www.ijrat.org}

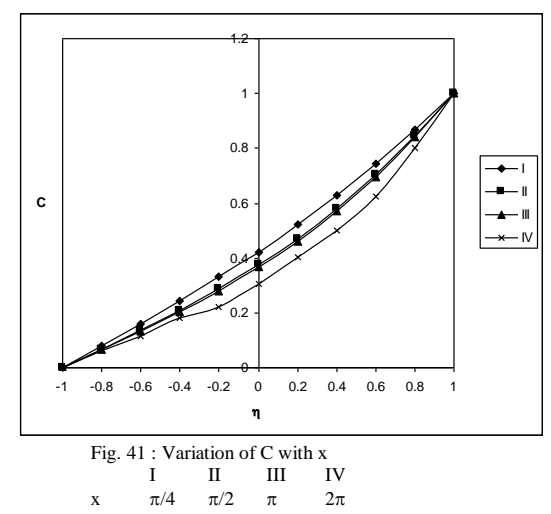

The Nusselt number $(\mathrm{Nu})$ at $\eta= \pm 1$ is shown in tables 1- 6 for different values of $\mathrm{G}, \mathrm{M}$, $\mathrm{D}^{-1}, \alpha, \beta, \gamma, \mathrm{K}, \mathrm{N}$ and $\mathrm{x}$. The rate of heat transfer depreciates at $\eta=+1$ and enhances at $\eta=-1$ with increase in $\mathrm{G}>0$ while for $\mathrm{G}<0,|\mathrm{Nu}|$ enhances at $\eta=+1$ and reduces at $\eta=-1$. The variation of $\mathrm{Nu}$ with Hartmann number $M$ shows that higher the Lorentz force smaller $|\mathrm{Nu}|$ at $\eta= \pm 1$. An increase in the strength of the heat source enhances $|\mathrm{Nu}|$ at $\eta=$ +1 and reduces at $\eta=-1$. The influence of surface geometry on $\mathrm{Nu}$ is shown in tables $1 \& 3$. It is observed that greater the constriction of the channel walls larger $|\mathrm{Nu}|$ at $\eta=+1$ and smaller $|\mathrm{Nu}|$ at $\eta=$ 1. Also $|\mathrm{Nu}|$ enhances with increase in the Womersley number $\gamma$ at both the walls(tables $1 \&$ $3)$. The variation of $\mathrm{Nu}$ with chemical reaction parameter $\mathrm{k}$ shows that higher the chemical reaction parameter $\mathrm{k}$ smaller $|\mathrm{Nu}|$ at $\eta=+1$ and smaller at $\eta=-1$. When the molecular buoyancy force dominates over the thermal buoyancy force the rate of heat transfer reduces at both the walls when the buoyancy forces act in the same direction and for the forces acting in opposite directions it enhances at $\eta=+1$ and reduces at $\eta=-1$ (tables $2 \&$ $5)$. With reference to the Darcy parameter $D^{-1}$ we find that an increase in $\mathrm{D}^{-1}$ results in an enhancement in $|\mathrm{Nu}|$ at both the walls. An increase in the Prandtl number $\mathrm{P}$ results in a depreciation in $|\mathrm{Nu}|$ at both the walls. Moving along the axial direction of the channel walls the rate of heat transfer enhances with $x$ at $\eta=+1$ while reduces at $\eta=-1$ (tables3\&6).

The rate of mass transfer (Sh) at $\eta= \pm 1$ is shown in tables $7-10$ for different parametric values. It is found that the rate of mass transfer enhances with increase in $G>0$ and reduces with $|G|$ at both the walls. An increase in $\mathrm{M}$ leads to a depreciation in $|\mathrm{Sh}|$ at $\eta=+1$ while at $\eta=-1$, it reduces with $\mathrm{M} \leq 5$ and enhances with higher $M \geq 10$. The variation of Sh with $\beta$ shows that greater the constriction of the channel walls larger $|\mathrm{Sh}|$ at $\eta=+1$ and smaller at $\eta$ $=-1$. $|\mathrm{Sh}|$ enhances at $\eta=+1$ and reduces at $\eta=-1$ with increase in $\gamma$. An increase in $\mathrm{D}^{-1}$ results in an enhancement in the rate of mass transfer at $\eta=+1$ and at $\eta=-1$,it enhances with increase in $\mathrm{D}^{-1} \leq 2 \times 10^{2}$ and reduces with higher $\mathrm{D}^{-1} \geq 3 \times 10^{2}$. The variation of Sh with K shows that an increase in the chemical reaction parameter $\mathrm{k}$ enhances $|\mathrm{Sh}|$ at $\eta=+1$ and reduces at $\eta=-1$ (tables $7 \& 9$ ). The variation of $\mathrm{Sh}$ with buoyancy ratio $\mathrm{N}$ shows that $|\mathrm{Sh}|$ reduces with $|\mathrm{N}|$ irrespective of the directions of the buoyancy forces. Also lesser the molecular diffusivity larger $|\mathrm{Sh}|$ at $\eta=+1$ and smaller at $\eta=-1$ (tables $8 \& 11$ ). Moving along the axial direction of the channel walls the rate of mass transfer enhances at $\eta=+1$ and reduces at $\eta=-1$ with increase in $x$ (tables $9 \&$ 12).

Table 1: Nusselt number $(\mathrm{Nu})$ at $\eta=+1$

\begin{tabular}{|l|l|l|l|l|l|l|l|l|l|l|}
\hline $\mathrm{G}$ & $\mathrm{I}$ & II & III & IV & V & VI & VII & VIII & IX & X \\
\hline $10^{3}$ & 0.403 & 0.22834 & 0.1391 & 0.5087 & 0.5563 & 0.44518 & 0.35095 & 0.2878 & 0.4033 & 0.40251 \\
\hline $3 \times 10^{3}$ & 0.3913 & 0.19911 & 0.0914 & 0.5014 & 0.551 & 0.43219 & 0.34069 & 0.2793 & 0.3915 & 0.39071 \\
\hline$-10^{3}$ & 0.4266 & 0.28681 & 0.2345 & 0.5233 & 0.5669 & 0.47116 & 0.37148 & 0.3046 & 0.4269 & 0.42611 \\
\hline$-3 \times 10^{3}$ & 0.4383 & 0.31604 & 0.2822 & 0.5306 & 0.5722 & 0.48414 & 0.38414 & 0.3817 & 0.4131 & 0.4379 \\
\hline $\mathrm{M}$ & 2 & 4 & 6 & 2 & 2 & 2 & 2 & 2 & 2 & 2 \\
\hline$\alpha$ & 2 & 2 & 2 & 4 & 6 & 2 & 2 & 2 & 2 & 2 \\
\hline$\beta$ & -0.5 & -0.5 & -0.5 & -0.5 & -0.5 & -0.3 & -0.7 & -0.9 & -0.5 & -0.5 \\
\hline$\gamma$ & 0.5 & 0.5 & 0.5 & 0.5 & 0.5 & 0.5 & 0.5 & 0.5 & 1.5 & 2.5 \\
\hline
\end{tabular}

Table 2: Nusselt number $(\mathrm{Nu})$ at $\eta=+1$ 
Available online at www.ijrat.org

\begin{tabular}{|l|l|l|l|l|l|l|l|l|}
\hline $\mathrm{G}$ & $\mathrm{I}$ & $\mathrm{II}$ & $\mathrm{II}$ & $\mathrm{IV}$ & $\mathrm{V}$ & $\mathrm{VI}$ & VII & VIII \\
\hline $10^{3}$ & 0.40303 & 0.42303 & 0.4303 & 0.2592 & 2.40438 & 3.4837 & 0.45678 & 0.50123 \\
\hline $3 \times 10^{3}$ & 0.39127 & 0.41127 & 0.44127 & 0.25163 & 2.33417 & 3.2491 & 0.40234 & 0.42356 \\
\hline$-10^{3}$ & 0.42657 & 0.44657 & 0.46657 & 0.27434 & 2.54481 & 3.953 & 0.44678 & 0.48790 \\
\hline$-3 \times 10^{3}$ & 0.43834 & 0.46834 & 0.48834 & 0.28191 & 2.61502 & 3.1876 & 0.46896 & 0.50123 \\
\hline $\mathrm{K}$ & 0.5 & 1.5 & 2.5 & 0.5 & 0.5 & 0.5 & 0.5 & 0.5 \\
\hline $\mathrm{N}$ & 1 & 1 & 1 & 2 & -0.5 & -0.8 & 1 & 1 \\
\hline $\mathrm{D}-1$ & 102 & 102 & 102 & 102 & 102 & 102 & $2 \times 102$ & $3 \times 102$ \\
\hline
\end{tabular}

Table 3: Nusselt number $(\mathrm{Nu})$ at $\eta=+1$

\begin{tabular}{|l|l|l|l|l|l|l|}
\hline $\mathrm{G}$ & $\mathrm{I}$ & $\mathrm{II}$ & $\mathrm{III}$ & $\mathrm{IV}$ & $\mathrm{V}$ & $\mathrm{VI}$ \\
\hline $10^{3}$ & 0.40303 & 0.48231 & 0.49346 & 0.52347 & 0.4033 & 0.40316 \\
\hline $3 \times 10^{3}$ & 0.39127 & 0.46824 & 0.47908 & 0.49908 & 0.39151 & 0.39136 \\
\hline$-10^{3}$ & 0.42657 & 0.51043 & 0.52224 & 0.54224 & 0.42688 & 0.42674 \\
\hline$-3 \times 10^{3}$ & 0.43834 & 0.64582 & 0.53662 & 0.56663 & 0.43867 & 0.43853 \\
\hline $\mathrm{x}$ & $\pi / 4$ & $\pi / 2$ & $\pi$ & $2 \pi$ & $\pi / 4$ & $\pi / 4$ \\
\hline $\mathrm{P}$ & 0.71 & 0.71 & 0.71 & 0.71 & 7 & 10 \\
\hline
\end{tabular}

Table 4 : Nusselt number $(\mathrm{Nu})$ at $\eta=-1$

\begin{tabular}{|l|l|l|l|l|l|l|l|l|l|l|}
\hline $\mathrm{G}$ & $\mathrm{I}$ & $\mathrm{II}$ & $\mathrm{III}$ & $\mathrm{IV}$ & $\mathrm{V}$ & $\mathrm{VI}$ & $\mathrm{VII}$ & $\mathrm{VIII}$ & $\mathrm{IX}$ & $\mathrm{X}$ \\
\hline $10^{3}$ & -0.7041 & -0.38079 & -0.286 & -0.69294 & -0.6892 & -0.70343 & -0.70504 & -0.70665 & -0.7053 & -0.7 \\
\hline $3 \times 10^{3}$ & -0.7234 & -0.41937 & -0.3438 & -0.70258 & -0.6957 & -0.72273 & -0.72434 & -0.72596 & -0.7247 & -0.72 \\
\hline$-10^{3}$ & -0.6655 & -0.30363 & -0.1702 & -0.67365 & -0.6764 & -0.66484 & -0.66643 & -0.66803 & -0.6666 & -0.67 \\
\hline$-3 \times 10^{3}$ & -0.6462 & -0.26505 & -0.1124 & -0.664 & -0.6699 & -0.64554 & -0.64713 & -0.64873 & -0.6473 & -0.65 \\
\hline $\mathrm{M}$ & 2 & 5 & 10 & 2 & 2 & 2 & 2 & 2 & 2 & 2 \\
\hline$\alpha$ & 2 & 2 & 2 & 4 & 6 & 2 & 2 & 2 & 2 & 2 \\
\hline$\beta$ & -0.5 & -0.5 & -0.5 & -0.5 & -0.5 & -0.3 & -0.7 & -0.9 & -0.5 & -0.5 \\
\hline$\gamma$ & 0.5 & 0.5 & 0.5 & 0.5 & 0.5 & 0.5 & 0.5 & 0.5 & 1.5 & 2.5 \\
\hline
\end{tabular}

Table 5: Nusselt ber $(\mathrm{Nu})$ at $\eta=-1$

\begin{tabular}{|l|l|l|l|l|l|l|l|l|}
\hline $\mathrm{G}$ & $\mathrm{I}$ & $\mathrm{II}$ & $\mathrm{III}$ & $\mathrm{IV}$ & $\mathrm{V}$ & $\mathrm{VI}$ & $\mathrm{VII}$ & $\mathrm{VIII}$ \\
\hline $10^{3}$ & -0.70407 & -0.66407 & -0.62407 & -0.36862 & 1.92885 & 1.10351 & -0.723435 & -0.756784 \\
\hline $3 \times 10^{3}$ & -0.72337 & -0.70337 & -0.6437 & -0.37872 & 1.98172 & 1.13376 & -0.754687 & -0.778976 \\
\hline$-10^{3}$ & -0.66546 & -0.62546 & -0.60546 & -0.34841 & 1.8231 & 1.04301 & -0.698765 & -0.698765 \\
\hline$-3 \times 10^{3}$ & -0.64616 & -0.60616 & -0.54616 & -0.3383 & 1.77022 & 1.01276 & -0.667895 & -0.689767 \\
\hline $\mathrm{k}$ & 0.5 & 1.5 & 2.5 & 0.5 & 0.5 & 0.5 & 0.5 & 0.5 \\
\hline $\mathrm{N}$ & 1 & 1 & 1 & 2 & -0.5 & -0.8 & 1 & 1 \\
\hline $\mathrm{D}-1$ & 102 & 102 & 102 & 102 & 102 & 102 & $2 \times 102$ & $3 \times 102$ \\
\hline
\end{tabular}

Table 6: Nusselt number $(\mathrm{Nu})$ at $\eta=-1$

\begin{tabular}{|l|l|l|l|l|l|l|}
\hline $\mathrm{G}$ & $\mathrm{I}$ & $\mathrm{II}$ & $\mathrm{III}$ & $\mathrm{IV}$ & $\mathrm{V}$ & $\mathrm{VI}$ \\
\hline $10^{3}$ & -0.70407 & -0.70296 & -0.70282 & -0.66282 & -0.70538 & -0.70543 \\
\hline $3 \times 10^{3}$ & -0.72337 & -0.72225 & -0.72212 & -0.70212 & -0.72473 & -0.72479 \\
\hline$-10^{3}$ & -0.66546 & -0.66436 & -0.66423 & -0.62423 & -0.66668 & -0.6667 \\
\hline$-3 \times 10^{3}$ & -0.64616 & -0.88983 & -0.64494 & -0.62494 & -0.64732 & -0.64734 \\
\hline $\mathrm{X}$ & $\pi / 4$ & $\pi / 2$ & $\pi$ & $2 \pi$ & $\pi / 4$ & $\pi / 4$ \\
\hline $\mathrm{P}$ & 0.71 & 0.71 & 0.71 & 0.71 & 7 & 10 \\
\hline
\end{tabular}

Table 7 : Sherwood Number (Sh) at $\eta=+1$

\begin{tabular}{|l|l|l|l|l|l|l|l|l|l|l|}
\hline $\mathrm{G}$ & I & II & III & IV & V & VI & VII & VIII & IX & X \\
\hline $10^{3}$ & 1.8103 & 0.60319 & 0.39547 & 2.11744 & 1.56459 & 1.37068 & 1.81109 & 1.81501 & 1.85678 & 1.88909 \\
\hline $3 \times 10^{3}$ & 1.84731 & 0.64906 & 0.45653 & 2.16972 & 1.58989 & 1.3871 & 1.8481 & 1.85202 & 1.89075 & 1.90678 \\
\hline$-10^{3}$ & 1.73628 & 0.51144 & 0.27333 & 2.01287 & 1.51399 & 1.33783 & 1.73707 & 1.741 & 1.77895 & 1.79095 \\
\hline$-3 \times 10^{3}$ & 1.69927 & 0.46557 & 0.21226 & 1.96059 & 1.4887 & 1.32141 & 1.70006 & 1.70399 & 1.71234 & 1.72345 \\
\hline
\end{tabular}


International Journal of Research in Advent Technology, Vol.7, No.2, February 2019

E-ISSN: 2321-9637

Available online at $w w w . i j r a t . o r g$

\begin{tabular}{|l|l|l|l|l|l|l|l|l|l|l|}
\hline $\mathrm{M}$ & 2 & 5 & 10 & 2 & 2 & 2 & 2 & 2 & 2 & 2 \\
\hline$\beta$ & -0.5 & -0.5 & -0.5 & -0.3 & -0.7 & -0.9 & -0.5 & -0.5 & -0.5 & -0.5 \\
\hline$\gamma$ & 0.5 & 0.5 & 0.5 & 0.5 & 0.5 & 0.5 & 1.5 & 2.5 & & \\
\hline
\end{tabular}

Table 8 : Sherwood Number (Sh) at $\eta=+1$

\begin{tabular}{|l|l|l|l|l|l|l|l|l|l|l|l|}
\hline $\mathrm{G}$ & $\mathrm{I}$ & $\mathrm{II}$ & $\mathrm{III}$ & IV & V & VI & VII & VIII & IX & X & XI \\
\hline $10^{3}$ & 1.8103 & 4.11712 & 8.25034 & 0.56484 & -0.785 & -0.60974 & 1.16039 & 1.36672 & 2.32543 & $2 . .01234$ & 2.12356 \\
\hline $3 \times 10^{3}$ & 1.84731 & 4.17459 & 8.34212 & 0.57639 & -0.801 & -0.62221 & 1.19123 & 1.39955 & 2.36716 & 2.29765 & 2.45223 \\
\hline$-10^{3}$ & 1.73628 & 4.00218 & 8.06678 & 0.54175 & -0.753 & -0.58481 & 1.09871 & 1.30106 & 2.24196 & 1.75678 & 1.79865 \\
\hline$-3 \times 10^{3}$ & 1.69927 & 3.94471 & 7.97501 & 0.5302 & -0.736 & -0.57235 & 1.06787 & 1.26824 & 2.20023 & 1.7579 & 1.78567 \\
\hline $\mathrm{K}$ & 0.5 & 1.5 & 2.5 & 0.5 & 0.5 & 0.5 & 0.5 & 0.5 & 0.5 & 0.5 & 0.5 \\
\hline $\mathrm{N}$ & 1 & 1 & 1 & 2 & -0.5 & -0.8 & 1 & 1 & 1 & 1 & 1 \\
\hline Sc & 1.3 & 1.3 & 1.3 & 1.3 & 1.3 & 1.3 & 0.24 & 0.6 & 2.01 & 1.3 & 1.3 \\
\hline $\mathrm{D}-1$ & 102 & 102 & 102 & 102 & 102 & 102 & 102 & 102 & 102 & $2 \times 102$ & $3 \times 102$ \\
\hline
\end{tabular}

Table 9: Sherwood Number (Sh) at $\eta=+1$

\begin{tabular}{|l|l|l|l|l|}
\hline $\mathrm{G}$ & I & II & III & IV \\
\hline $10^{3}$ & 1.8103 & 2.54502 & 2.72268 & 2.72274 \\
\hline $3 \times 10^{3}$ & 1.8473 & 2.61957 & 2.80678 & 2.80685 \\
\hline$-10^{3}$ & 1.7363 & 2.39591 & 2.55447 & 2.55452 \\
\hline$-3 \times 10^{3}$ & 1.6993 & 1.41265 & 2.47036 & 2.47041 \\
\hline $\mathrm{x}$ & $\pi / 4$ & $\pi / 2$ & $\pi$ & $2 \pi$ \\
\hline
\end{tabular}

Table 10: Sherwood Number (Sh) at $\eta=-1$

\begin{tabular}{|l|l|l|l|l|l|l|l|l|l|l|l|l|}
\hline $\mathrm{G}$ & $\mathrm{I}$ & $\mathrm{II}$ & III & IV & V & VI & VII & VIII & IX & $\mathrm{X}$ & $\mathrm{XI}$ & $\mathrm{XII}$ \\
\hline $10^{3}$ & 0.4595 & 0.2541 & 0.1971 & 0.47742 & 0.45924 & 0.4584 & 0.45924 & 0.4584 & 0.48976 & 0.46578 & 0.48976 & 0.3549 \\
\hline $3 \times 10^{3}$ & 0.4761 & 0.2873 & 0.2469 & 0.48525 & 0.47586 & 0.475 & 0.47586 & 0.475 & 0.50123 & 0.48765 & 0.52165 & 0.38765 \\
\hline$-10^{3}$ & 0.4262 & 0.1876 & 0.0974 & 0.46175 & 0.426 & 0.4251 & 0.426 & 0.4251 & 0.445676 & 0.43256 & 0.45676 & 0.3546 \\
\hline$-3 \times 10^{3}$ & 0.4096 & 0.1544 & 0.0475 & 0.45392 & 0.40938 & 0.4085 & 0.40938 & 0.4085 & 0.42345 & 0.41237 & 0.43256 & 0.3023 \\
\hline $\mathrm{M}$ & 2 & 5 & 10 & 2 & 2 & 2 & 2 & 2 & 2 & 2 & 2 & 2 \\
\hline$\beta$ & -0.5 & -0.5 & -0.5 & -0.3 & -0.7 & -0.9 & -0.5 & -0.5 & -0.5 & -0.5 & -0.5 & -0.5 \\
\hline$\gamma$ & 0.5 & 0.5 & 0.5 & 0.5 & 0.5 & 0.5 & 1.5 & 2.5 & 0.5 & 0.5 & 0.5 & 0.5 \\
\hline $\mathrm{D}-1$ & 102 & 102 & 102 & 102 & 102 & 102 & 102 & 102 & 102 & 102 & $2 \times 102$ & $3 \times 102$ \\
\hline
\end{tabular}

Table 11 : Sherwood Number (Sh) at $\eta=-1$

\begin{tabular}{|l|l|l|l|l|l|l|l|l|l|}
\hline $\mathrm{G}$ & I & II & III & IV & V & VI & VII & VIII & IX \\
\hline $10^{3}$ & 0.45945 & 0.37524 & 0.31068 & 0.23087 & -0.9470 & -0.5874 & 0.51625 & 0.48635 & 0.43414 \\
\hline $3 \times 10^{3}$ & 0.47607 & 0.39502 & 0.33338 & 0.23922 & -0.9813 & -0.6086 & 0.4705 & 0.50207 & 0.45165 \\
\hline$-10^{3}$ & 0.42621 & 0.33568 & 0.26528 & 0.21417 & -0.8785 & -0.5449 & 0.45525 & 0.45491 & 0.39912 \\
\hline$-3 \times 10^{3}$ & 0.4096 & 0.3159 & 0.24258 & 0.20582 & -0.8443 & -0.5237 & 0.48635 & 0.43919 & 0.38161 \\
\hline $\mathrm{K}$ & 0.5 & 1.5 & 2.5 & 0.5 & 0.5 & 0.5 & 0.5 & 0.5 & 0.5 \\
\hline $\mathrm{N}$ & 1 & 1 & 1 & 2 & -0.5 & -0.8 & 1 & 1 & 1 \\
\hline $\mathrm{Sc}$ & 1.3 & 1.3 & 1.3 & 1.3 & 1.3 & 1.3 & 0.24 & 0.6 & 2.01 \\
\hline
\end{tabular}

Table 12 : Sherwood Number (Sh) at $\eta=-1$

\begin{tabular}{|l|l|l|l|l|}
\hline $\mathrm{G}$ & $\mathrm{I}$ & $\mathrm{II}$ & $\mathrm{III}$ & $\mathrm{IV}$ \\
\hline $10^{3}$ & 0.45945 & 0.43866 & 0.43485 & 0.4248 \\
\hline $3 \times 10^{3}$ & 0.47607 & 0.46925 & 0.46867 & 0.46067 \\
\hline$-10^{3}$ & 0.42621 & 0.37749 & 0.36722 & 0.36021 \\
\hline$-3 \times 10^{3}$ & 0.40964 & 0.41152 & 0.3334 & 0.3304 \\
\hline $\mathrm{x}$ & $\pi / 4$ & $\pi / 2$ & $\pi$ & $2 \pi$ \\
\hline
\end{tabular}




\section{REFERENCES:}

[1] Angirasaa D Peterson G P and Pop I(1997): Combined heat and mass transfer by natural convection with opposing buoyancy effects in a fluid saturated porous medium, Int.J.Heat Mass Transfer,V.40,pp.2755-2773.

[2] BejanA and KhairKR(1985): Heat and Mass transfer by natural convection in a porous medium, Int.J.Heat Mass transfrt,V.28,pp.908918.

[3] Chamkha A.J, Takhar H.S and Soundalgekar V.M(2001): Radiation effects on free convection flow past a semi-inifinte vertical plate with mass transfer, Chem.Engng.J,V.84,pp.335-342.

[4] 4. Comini.G, C.Nonino and S.Savino(2002): Convective heat and mass transfer in wavy finned-tube exchangers, International journals of Numerical Methods for Heat and Fluid flow,V.12,i.6,p.735-755.

[5] Cheng $\mathrm{P}(1978)$ : Heat transfer in geothermal systems, Adv.Heat Transfer,V.14,pp.1-105.

[6] Deshikachar K.S and Ramachandra Rao A(1985). Effect of a magnetic field on the flow and blood oxygenation in channel of variable cross-section, Int. J. Engg Sci,V.23,pp-1121.

[7] Das U.N, Deka R.K and Soundalgekar V.M(1994): Effects of mass transfer on flow past an impulsively started infinite vertical plate with constant heat flux and chemical reaction,Forschungim

Ingenieurwesen,V.60,pp.284-309.

[8] Gagan S (1985): Proceedings of Natural heat and mass transfer conference, Visakhapatnam,India.

[9] Gnaneswar reddy(2008): Radiation and mass transfer on an unsteady two-dimensional laminar convective boundary layer flow of a viscous incompressible chemically reacting fluid.Acta Ciencia Indica, V.34M, No,21, p.639.

[10] Hussain M.A and Takhar H.S(1996): Radiation effect on mixed convection along a vertical plate with uniform surface temperature, Heat and Mass transfer,V.31,pp.243-248.

[11] Hyan Goo Kwon, Sang Dong Hwang and Hyung Hee Cho(2008): Flow and heat/mass transfer in a wavy duct with various corrugation angles in two dimensional flow regimes, Heat and Mass Transfer,V.45,p.157-165.

[12] Jer-Huan-Jang,W.M.Yan(2004): Mixed convection heat mass transfer along a vertical wavy surface, Int. J. Heat Mass. Transfer,V.47,pp.419-428.

[13] Lai F.C(1971): Coupled heat and mass transfer by mixed convection from a vertical plate in a saturated porous medium., Int.Commn.heat mass transfer,V.18,pp.93-106.

[14]Lai,F.C and Kulacki F.A(1991): Coupled heat and mass transfer by natural convection from vertical surfaces in porous medium., Int.J.Heat Mass Transfer, V.34, pp.1189- 1194.

[15] Kandaswamy P,Abd.Wahid B.Md.Raj, azme B.Khamis(2006): Effects of chemical reaction, heat and mass transfer on boundary layer flow over a porous wedge with heat radiation in the presence of suction or injection, Theoret.Appl.Mech.,V.33.No.2,pp.123-148.

[16] Kumar H(2011): Heat transfer with radiation and temperature dependent heat source in MHD free convective flow confined between two vertical wavy walls, Int. J. of Appl. Math and Mech.V.7(2),pp.77-103.

[17]Lee T. S, Parikh P. G, Archivos, A and Bershader ,D(1982): Natural convection in a vertical channel with opposing buoyancy forces. Int. J. Heat Mass Transfer,V.25,pp.499-522.

[18] Mahdy A(2008): Mixed convective heat and mass transfer on a vertical wavy plate embedded in a saturated porous media (PST/PSC)., Int. J. Appl. Mathand Mech.,V.5 (7),pp.88-97.

[19] McMichael M and Deutsch S(1984): Magneto hydrodynamics of laminar flow in slowly varying tube in an axial magnetic field. Phy, Fluids,V.27,p.110.

[20] MurthyP.V.S.N and SinghP(1990): Heat and Mass transfer by natural convection in a NonDarcy porous medium,Acta Mech,V.26,pp.567.

[21] Muthukumaraswamy $R$ and GanesanP(2002): Diffusion and first order chemical reaction on impulsively started infinite vertical plate with variable temperature, Int.J. Ther. Sci, 412(5), pp. 475-479.

[22] Muthukumaraswamy $R(2002)$ : Effects of a chemical reaction on a moving isothermal surface with suction,Acta Mechnica,V.155,pp.65-72.

[23] Muthuraj R and Srinivas S(2010): Mixed convective heat and mass transfer in a vertical wavy channel with traveling thermal wavy and porous medium, Computers and mathematics with applications, 59,pp. 3516-3528.

[24] Narahari M(2009): Oscillatory plate temperature effects of free convection flow of dissipative fluid between long vertical parallel plates. Int.J.of Appl. Math. And Mech 5(3),pp 30-46.

[25] Nelson D.J and Wood B.D(1986): Combined heat and mass transfer by natural convection between vertical plates with uniform flux boundary conditions, Heat transfer,V.4,pp.1587-1952.

[26] Nelson D.J and Wood B.D(1989): Combined heat and mass transfer by natural convection between vertical plates ,Int.J.,Heat Mass transfer,V.82,pp.1789-1792.

[27] Prakash J and Ogulu(2006):Unsteady 2-D flow of a radiations and chemically reacting MHD fluid with time dependent suction. Ind.J.Pure and Applied Maths,V.44,P.805-810. 
[28] Prasad V, Kulacku F.A and Keyhani M(1985): Natural convection in a porous medium,J.Fluid Mech.,V.150,pp.89-119.

[29] Prasada Rao D.R.V, Krishna D.V and Debnath L (1983). Free convection in Hydromagnetic flows in a vertical wavy channel, Int. Engg.Sci, V.21, No.9, pp.1025-1039.

[30] Raptis A(1998): Radiation and free convection flow through a porous medium,Int.Comm.Heat Mass transfer,25(2),pp.289-295.

[31] Raptis A.A and Perdikis C (1999): Radiation and free convection flow past a moving plate,Appl.Mech.Eng,Vol.4,pp 817-821.

[32] Soundalgekar V.M and Takhar H.S(1993):Radiation effects on free convection flow past a semi-infinite vertical plate. Modelling measurement and control,B.51,p.31-40.

[33] Sree Ramachandra Murthy A (1992): Buoyancy induced hydromagnetic flows through a porous medium-A study, Ph.D thesis, S.K.University, Anantapur,India.

[34] Sparrow E.M, Chryser $M$ and Azvedo L.F.A(1984):Observed flow reversals and measured-predicted Nusselt number for natural convection in a one sided heated vertical channel. J. Heat transfer,V.106, pp.325-332.

[35] Sparrow E.M and Azvedo L.F.A(1985):Vertical channel natural convection spanning between the fully-developed limit and the single-plate boundary-layer limit. $\mathrm{J}$.Heat and Mass transfer,V.28, pp.1847-1857.

[36] Sudha Mathew(2009): Hydro magnetic mixed convective heat and mass transfer through a porous medium in a vertical channel with thermodiffusion effect.Ph.D thesis,S,K.University,Anantapur,India.

[37] Trevison D.V and Bejan A(1987): Combined heat and mass transfer by natural convection in vertical enclosure,Trans.ASME,V.109,pp.104111.

[38] Vajravelu K and Ali Neyfeh (1981): Influence of wall waviness on friction and pressure drop in channels, Int. J. Maths and Math. Sc.,V.4,pp.805818.

[39] Vajravelu K and Sastry K.S. (1978): Heat transfer in a viscous incompressible fluid confined between a long vertical wavy wall and a parallel flat wall, J.Fluid Mech.V.86,No.2,p.365.

[40] Vajravelu K and Debnath L : Non-linear study of convective heat transfer and fluid flows induced by traveling thermal waves, Acta Mech.V.59,pp 233-249.

[41] Wei-Mon Yan(1996): Combined buoyancy effects of thermal and mass diffusion on laminar forced convection in horizontal rectangular ducts, Int.J, Heat Mass transfer,V.39,pp.1479-1488. 